\title{
Early Diagnosis And Management Of Malignant Distal Biliary Obstruction: A Review On Current Recommendations And Guidelines
}

This article was published in the following Dove Press journal:

Clinical and Experimental Gastroenterology

\author{
Michael Fernandez Y Viesca \\ Marianna Arvanitakis \\ Department of Gastroenterology, \\ Hepatopancreatology and Digestive \\ Oncology, Erasme Hospital, Univertié \\ Libre de Bruxelles (ULB), Brussels, \\ Belgium
}

\begin{abstract}
Malignant biliary obstruction is a challenging condition, requiring a multimodal approach for both diagnosis and treatment. Pancreatic adenocarcinoma and cholangiocarcinoma are the leading causes of malignant distal biliary obstruction. Early diagnosis is difficult to establish as biliary obstruction can be the first presentation of the underlying disease, which can already be at an advanced stage. Consequently, the majority of patients (70\%) with malignant distal biliary obstruction are unresectable at the time of diagnosis. The association of clinical findings, laboratory tests, imaging, and endoscopic modalities may help in identifying the underlying cause. Novel endoscopic techniques such as cholangioscopy, intraductal ultrasonography, or confocal laser endomicroscopy have been developed with promising results, but are not used in routine clinical practice. As the number of patients with malignant distal biliary obstruction who will undergo curative surgery is limited, endoscopy has a crucial role in palliation, to relieve biliary obstruction According to the last European guidelines published in the management of biliary obstruction, selfexpandable metal stents have a central place in biliary drainage compared to plastic stents. Endoscopic ultrasound has evolved impressively in the last decades. When standard techniques of biliary cannulation by endoscopic retrograde cholangiopancreatography fail, endoscopic ultrasound-guided biliary drainage is a good option compared to percutaneous drainage.
\end{abstract}

Keywords: distal biliary stricture, pancreaticobiliary malignancy, preoperative biliary drainage, self-expandable metal stent, palliative biliary drainage

\section{Introduction}

Malignant distal biliary obstruction (MDBO) is still a diagnostic and a therapeutic challenge requiring a multidisciplinary approach. Diagnosis of the underlying disease is often made at an advanced stage, leading to poor outcomes, as well as causing debilitating symptoms and negatively affecting the quality of life of patients ${ }^{1}$. MDBO can be the initial presentation of the disease, such as painless jaundice in patients with pancreatic adenocarcinoma, or occur during the progression of the disease once the diagnosis is established. ${ }^{2}$ The role of the endoscopist can be crucial in the diagnostic, therapeutic and palliative management, depending on type and stage of the malignancy. This review aims to explore etiologies and diagnostic modalities as well as the role of endoscopy in the management of MDBO.

\section{Etiology, Epidemiology And Natural History}

MDBO is the result of an extrinsic bile duct compression or an intrinsic development, either primitive or secondary from metastases into the bile duct $^{3}$ The two
Correspondence: Marianna Arvanitakis Department of Gastroenterology, Hepatopancreatology and Digestive Oncology, Erasme Hospital, Univertie Libre De Bruxelles (ULB), Route De Tel $+32255537 / 2$ Email Marianna.Arvanitaki@erasme.ulb. ac.be 
main etiologies are pancreatic adenocarcinoma (mostly located in the head or the uncinate process) and cholangiocarcinoma (CCA). The other causes are represented by ampullary/duodenal carcinoma, gallbladder (GB) cancer and metastatic diseases that infiltrate the head of the pancreas and the common bile duct (Table 1). ${ }^{4}$ Pancreatic cancer is the second most common digestive cancer and will become the second leading cause of cancer-related death by $2030 .^{5}$ Approximatively $70 \%$ of patients with pancreatic cancer present with $\mathrm{MDBO} .{ }^{6} \mathrm{CCA}$ is the second most common hepatobiliary cancer in the world. Distal CCA (dCCA) accounts for approximately 20-30\% of all cholangiocarcinomas diagnosed worldwide. ${ }^{7}$ The global incidence of CCA is highest in Thailand with approximately 100 per 100,000 individuals and has been attributed to endemic liver-flukes infection, in particular with Clonorchis sinensis and Opisthorchis viverrini. ${ }^{7,8}$ In western countries, it ranges between $0.5-2.0$ per 100,000 individuals. ${ }^{7}$ The majority of cases are sporadic, but different factors causing ongoing chronic inflammation of the biliary tree, such as primary sclerosing cholangitis (PSC) and chronic infection, are often implicated. ${ }^{9}$ Other underlying conditions are fibropolycystic liver disease, Caroli's disease and choledochal cysts. ${ }^{9}$ GB adenocarcinoma is the fifth most common digestive cancer and the most common cancer involving the biliary tract worldwide. $^{10}$ Cholelithiasis is a well-described risk factor for GB cancer, although only $1-3 \%$ of patients with gallstones will develop GB cancer. ${ }^{11}$ Furthermore, porcelain gallbladder, gallbladder polyps, congenital biliary cysts, and abnormal pancreaticobiliary duct junction are associated with a higher risk of cancer of the GB. ${ }^{12}$ Ampullary cancers are rare, representing only $0.2 \%$ of digestive cancers and $7 \%$ of all periampullary cancers. They originate from the ampullary complex, at the end of the confluence of the common bile and pancreatic duct. ${ }^{13}$

\section{Diagnosis}

\section{Clinical Features And Initial Management}

The most common clinical presentations of pancreatobiliary cancers include jaundice, weight loss, and anorexia with significant impact on quality of life, morbidity, and mortality. ${ }^{3}$ MDBO leads to jaundice (conjunctiva and skin), discolored stools, dark urine, pruritus, nausea and vomiting. ${ }^{14-16}$ The clinical presentations of each etiology involved in MDBO are represented in the Table 1. A complete physical examination is necessary to identify jaundice, the presence of organomegaly or lymphadenopathy. Laboratory tests should include total bilirubin, conjugated bilirubin, alkaline phosphatase (ALP), gamma glutamyl transferase (GGT), alanine aminotransferase (ALT), aspartate aminotransferase (AST). Bilirubin levels have been consistently identified as a strong predictor of malignant disease, the higher the bilirubin level at presentation, the greater the likelihood of malignant disease. ${ }^{17}$ A large retrospective study of 830 patients showed that patients with a biliary stricture and completely normal liver function tests are unlikely to have a primary hepatopancreaticobiliary malignancy. ${ }^{18}$ Those presenting with normal bilirubin but an alteration of ALP and/or ALT are more likely to have a malignant disease, requiring a higher degree of clinical suspicion. ${ }^{18}$ The most common tumor markers used in the diagnosis or prognosis of pancreaticobiliary cancers are carbohydrate antigen 19-9 (CA 19-9) and carcinoembryonic antigen (CEA). A CA 19-9>37U/mL showed a sensitivity of approximately $74 \%$ in patients with MDBO but a very low specificity. ${ }^{19,20}$ Indeed CA 19-9 can also be increased in case of non-malignant pathologies including cholestasis, cholangitis, cirrhosis, acute pancreatitis and other cancers such as gastric and colon cancer. ${ }^{21}$ CEA showed $33-68 \%$ of sensitivity and $75-95 \%$ of specificity for cholangiocarcinoma. ${ }^{20}$ Although they may be useful as prognostic markers, their diagnostic usefulness is limited. ${ }^{22}$ New biomarkers such as Glypican-1 and micro RNA's for early detection of pancreatic cancer are currently being studied. ${ }^{22}$ Once pancreaticobiliary malignancy is suspected based on the history, physical examination, and initial laboratory test results, imaging studies such as transabdominal ultrasonography (TUS), computed tomography (CT) scan, or magnetic resonance imaging (MRI) and cholangiopancreatography (MRCP) are the next step to establish the diagnosis.

\section{Differential Diagnosis, Imaging And Endoscopic Modalities Ampullary Adenocarcinoma}

Ampullary adenocarcinoma is usually suspected based on the demonstration of obstructive jaundice, with dilatation of both the pancreatic and biliary duct up to the papilla, as seen on abdominal imaging studies. ${ }^{23}$ Relapsing cholangitis is a common presentation for ampullary adenocarcinoma. ${ }^{24}$ Rarely, it can be diagnosed incidentally by esophagogastroduodenoscopy in patients without jaundice. ${ }^{24}$ TUS may demonstrate biliary dilatation but it is not sensitive for detecting ampullary tumors, especially small tumors. CT-scan has an overall accuracy of $20 \%$ in detecting ampullary carcinoma. ${ }^{25}$ On the 


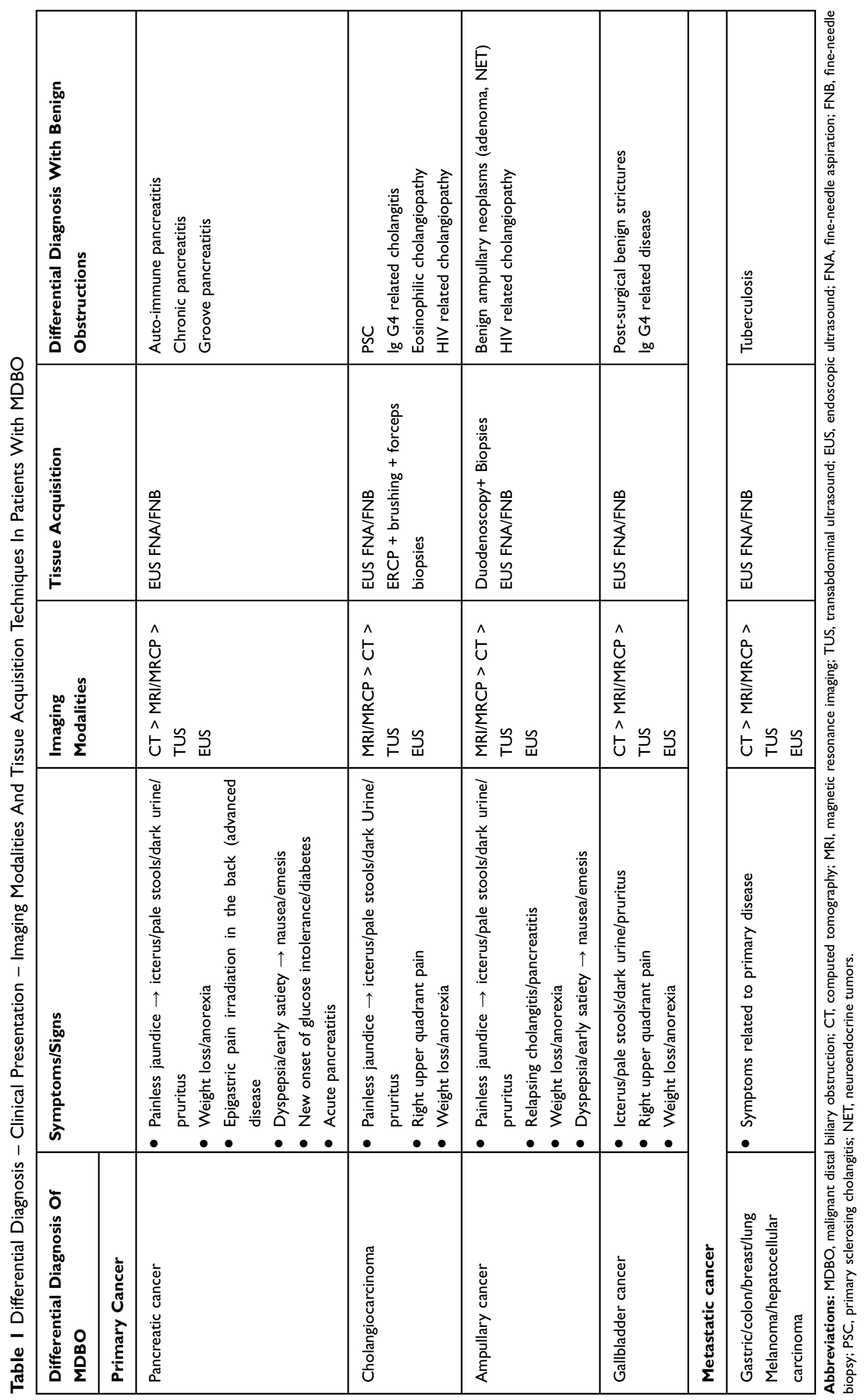


other hand, MRCP has a 76\% overall accuracy for detecting ampullary carcinoma but cannot always distinguish between tumors and other cause of ampullary obstructions as stones or benign strictures. ${ }^{26} \mathrm{CT}$-scan and MRCP are usually useful to confirm biliary/pancreatic duct dilatation and for the staging in case of advanced disease. ${ }^{24}$ Endoscopic retrograde cholangiopancreatography (ERCP) has a double role: diagnostic by detecting an ampullary abnormality and providing tissue samples, and therapeutic for relieving the biliary obstruction (Figure 1). ${ }^{26,27}$ Endoscopic ultrasound (EUS) is comparable to ERCP for the detection of ampullary adenocarcinoma and is the best modality to stage the disease to decide on the treatment (local resection vs pancreaticoduodenectomy). ${ }^{28,29}$ In a study of Cannon et al evaluating 50 patients with ampullary neoplasms, EUS seems to be more accurate than CTscan and MRI for T staging ( $78 \%$ for EUS vs $24 \%$ CT $\mathrm{p}<0.01$ and $78 \%$ for EUS vs $46 \%$ for MRI, $\mathrm{p}=0.07$ ). No statistical difference was observed for the $\mathrm{N}$ staging accuracy (68 vs $59 \%$ vs $77 \%, \mathrm{p}>0.05$ ). To note, EUS is less accurate in the presence of a biliary stent (non-stenting group, T: $83-84 \%$ and N: $100 \%$; stenting group, T: $71-72 \%$ and $\mathrm{N}: 75 \%) .{ }^{30} \mathrm{In}$ addition to its role for the staging, EUS provides the possibility to perform fine-needle aspiration (FNA) for tissue acquisition. ${ }^{24}$ According to previous studies, EUS-FNA for ampullary tumors has a diagnostic accuracy between $88 \%$ and $100 \% .^{31,32}$

\section{Pancreatic Cancer}

MDBO caused by pancreatic cancer is usually located in the head of the pancreas or the uncinate process. To establish the diagnosis and the stage of the disease, to evaluate the resectability and obtain a histopathological diagnosis, the evaluation will be carried out by one of the following modalities: TUS, CT, MRI/MRCP, EUS, and ERCP. Diagnostic accuracy of TUS is about 82 to $86 \%$ for the diagnosis pancreatic tumors located in the head. ${ }^{33}$ When the tumor is less than $3 \mathrm{~cm}$ of diameter, the diagnostic accuracy is lower, and TUS can rarely evaluate staging and resectability. ${ }^{34} \mathrm{CT}$-scan improves tumor detection, local and regional staging and evaluation for invasion of vascular structures to establish resectability (Figure 2). The sensitivity of multidetector CT-scan ranges from $89 \%$ to $95 \%,{ }^{35,36}$ and is currently the preferred modality for preoperative staging and assessment of resectability of a patient with pancreatic cancer. It is easily available, quickly performed and inexpensive. ${ }^{37,38} \mathrm{MRI} / \mathrm{MRCP}$ with either gadoliniumenhanced or mangafodipir enhanced sequences is as sensitive as CT-scan in detecting pancreatic cancer ${ }^{39}$ Fusari et al compared multidetector CT-scan vs MRI: diagnostic accuracy for tumor identification and resectability were comparable for both techniques; tumor identification CT/MRI: 98\%/98\%, resectability CT/MRI:94\%/90\% ${ }^{39}$ Roa et al also showed comparable results between CT-scan and MRI for characterization of $<2$ cm tumors. ${ }^{40} \mathrm{~A}$ recent meta-analyze, comparing CT-scan, MRI and other modalities such as positron emission tomography/computed tomography (PET/CT) and EUS-FNA showed that CT-scan and MRI had similar sensitivities and specificities for both diagnosis and vascular involvement. ${ }^{41} \mathrm{PET} / \mathrm{CT}$ is a molecular technique using fluorodeoxyglucose as a radiotracer. The reported sensitivity and specificity for the diagnosis range from $46-71 \%$ and $63-100 \%$, respectively. ${ }^{41} \mathrm{PET} / \mathrm{CT}$ sensitivity is better in the follow-up after chemo-radiotherapy, for detecting pancreatic cancer recurrence after surgery. ${ }^{41}$ It is also useful to identify metastases due to its anatomic coverage but is limited by false positive results. ${ }^{41}$ EUS is also a cornerstone in the work-up of pancreatic cancer. In the review of Dewitt et al (11 studies 678 patients), EUS had a greater sensitivity in tumor detection than CT-scan, also confirmed for tumors less than $3 \mathrm{~cm}$ of diameter. ${ }^{42}$ Concerning TNM classification, Dewitt et al and Soriano et al demonstrated that EUS was superior than CT-scan for $\mathrm{T}$ staging and an had an overall lower rate of overstaging compared to CT-scan and MRI. For the $\mathrm{N}$ staging accuracy, no superiority was observed; for the $\mathrm{M}$ staging, CT-scan was superior for the evaluation of distant metastases. ${ }^{42,43}$ Although CT-scan ls the most used imaging modality for initial staging of pancreatic cancer, EUS is valuable when CT-scan gives equivocal results about surrounding lymph nodes or tumors less than $3 \mathrm{~cm}$ and to obtain tissue samples. ${ }^{44}$ EUS-guided elastography, a method evaluating the tissues' stiffness has demonstrated promising results with a high sensitivity do determine malignancy, but a low specificity. ${ }^{45}$ Contrast-enhanced EUS (CE-EUS) is another diagnostic modality, involving micro-bubble injection to assess tumor vascularization. ${ }^{46}$ In a recent meta-analyze, CEEUS showed a pooled sensitivity and specificity of 0.91 and 0.86 respectively, for the differential diagnosis of pancreatic adenocarcinoma. ${ }^{46}$ With the improvements of imaging techniques and the emergence of EUS, ERCP has lost its supremacy for establishing the diagnosis and staging. Cholangiopancreatographic signs suggestive of pancreatic tumor on ERCP are a double duct sign (dilation of both pancreatic and biliary ducts), an abrupt and/or irregular cutoff of the biliary duct or a single long stricture $>1 \mathrm{~cm}$ of the pancreatic duct (Figure 2 ). ${ }^{47}$ Only $15-20 \%$ of patients presenting with imaging findings suggestive of pancreatic cancer are curative and will undergo surgery. ${ }^{48}$ According to the National comprehensive cancer network and the European Society for 
A

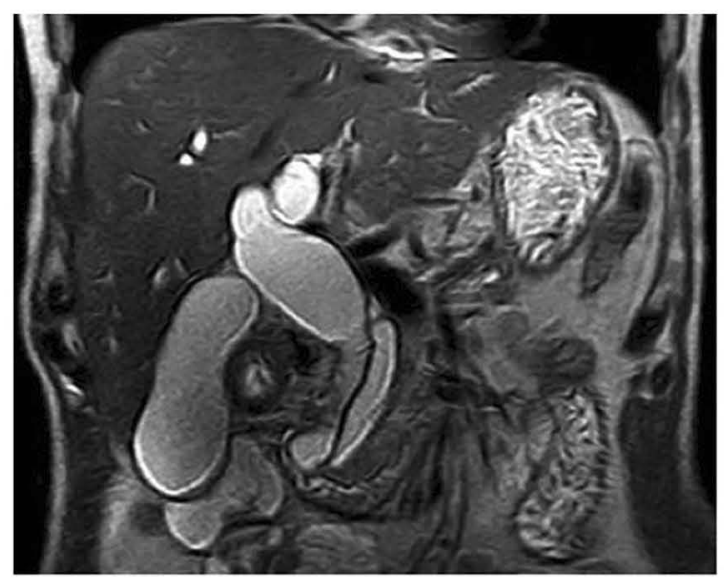

c

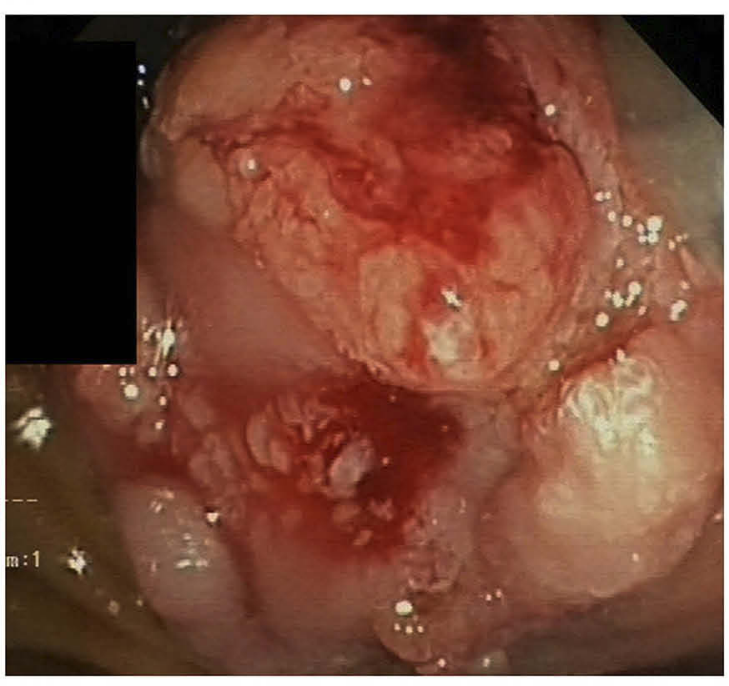

B

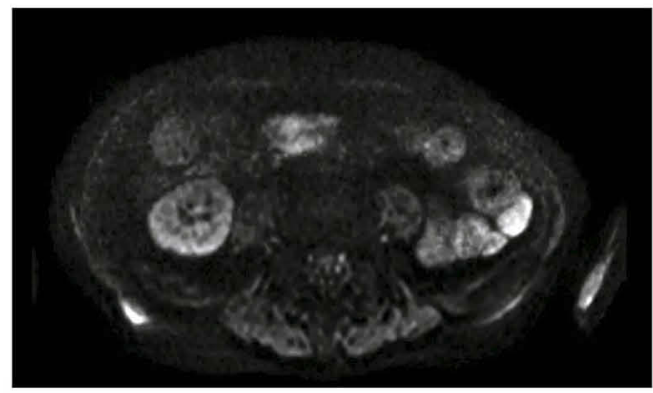

D

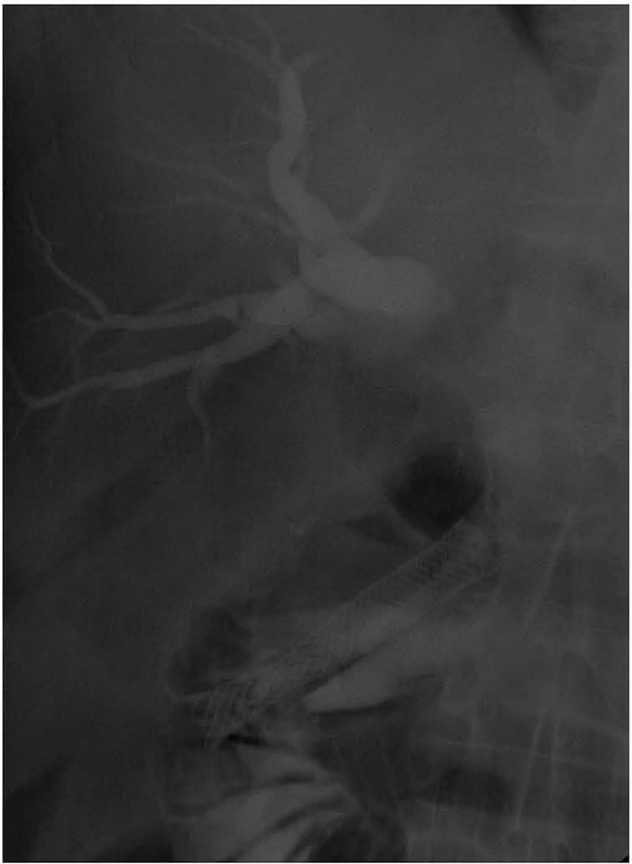

E

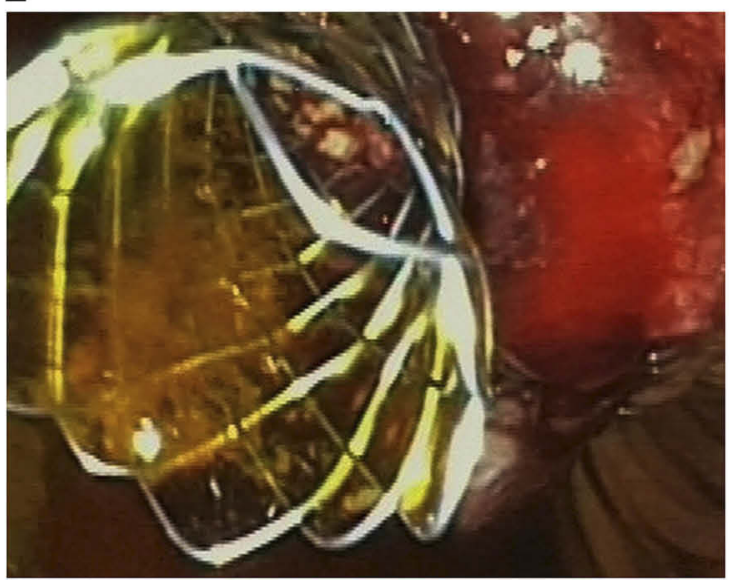

Figure I A 69-year-old presented with abdominal pain and cholestasis. MRI showed a double duct sign and a suspected lesion at the papillary area (A), presenting an abnormal diffusion-weighted signal and suggestive of an ampulloma (B). ERCP revealed an ampullary mass (C) and standard biopsies were performed confirming the diagnosis of ampullary carcinoma. A $10 \mathrm{~mm}$ USEMS of $6 \mathrm{~cm}$ of length is placed to relieve the obstruction (D, E).

Abbreviations: MRI, Magnetic resonance imaging; ERCP, Endoscopic retrograde cholangiopancreatography; USEMS, uncovered self-expandable metal stents.

Medical Oncology guidelines a biopsy proof is not required for early resectable pancreatic cancer. ${ }^{38,49,50}$ In the case of neoadjuvant treatment, advanced disease, such as borderline, locally advanced or metastatic cancer, and suspicion of other types of malignancies (such as lymphoma), tissue acquisition is unequivocal. ${ }^{49,51}$ Tissue sampling for pancreatic cancer is 
A

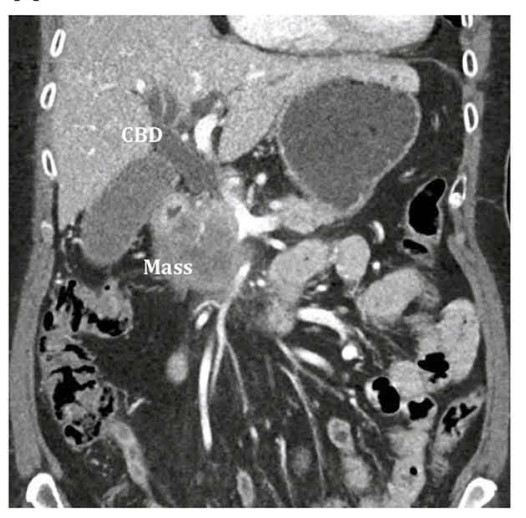

B

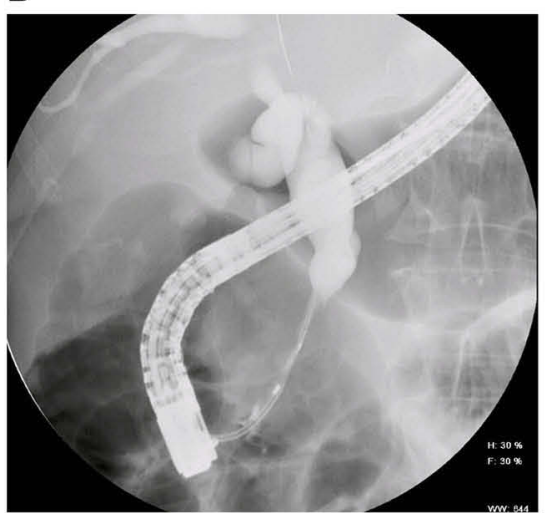

C

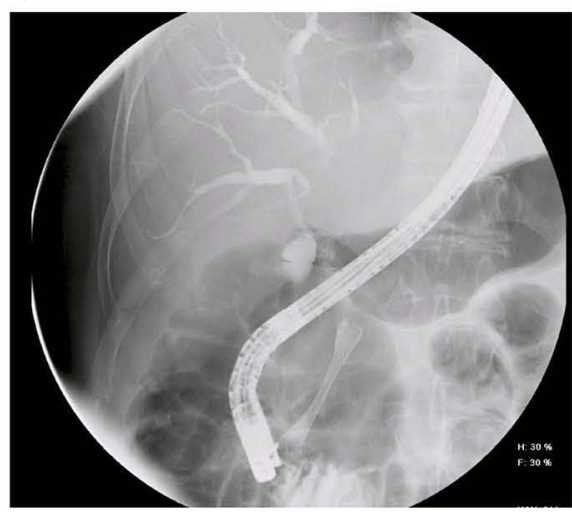

Figure 2 A 67-year-old woman presenting with dyspepsia, weight loss and jaundice. CT showed a $6 \mathrm{~cm}$ mass in the head of the pancreas with vascular involvement (SMV > $270^{\circ}$, SMA >120\%) compressing the distal CBD (A). Both EUS-FNB and ERCP with brushings confirmed non-resectable pancreatic adenocarcinoma (B). A I0mm USEMS 4cm was inserted to provide drainage before neoadjuvant chemotherapy $(\mathbf{C})$.

Abbreviations: SMV, superior mesenteric vein; SMA, superior mesenteric artery; CBD, common bile duct; EUS-FNB, endoscopic ultrasound fine needle biopsy; ERCP, Endoscopic retrograde cholangiopancreatography; USEMS, uncovered self-expandable metal stent.

obtained by EUS guided FNA or biopsy (FNB), as well as by brush cytology and biopsies during ERCP. ${ }^{52}$ In a meta-analyze of Chen and colleagues, EUS-FNA reached a sensitivity of $92 \%$ and a specificity of $96 \%$ for the diagnosis of pancreatic cancer. ${ }^{44} \mathrm{~A}$ second meta-analyze published by $\mathrm{Puli}^{53}$ and al (41 papers) showed similar results. The accuracy was lower in the setting of chronic pancreatitis; therefore, a negative FNA result does not exclude pancreatic cancer. Adverse events of EUSFNA are bleeding, pancreatitis, perforation and tumor seeding. ${ }^{54}$ In a prospective study of 355 patients who underwent EUS-FNA, adverse events were reported in $2.54 \%$ with 3 patients having developed pancreatitis and 3 others with tumor seeding into the gastrointestinal wall. ${ }^{54}$ There was also reports of peritoneal seeding but less compared to TUS-guided or CTguided percutaneous biopsies. ${ }^{55}$ Ikezawa and colleagues found that peritoneal carcinomatosis developed during the course of the disease in patients who had undergone EUS-FNA for pancreatic cancer in $17.9 \%$ compared with $14.9 \%$ when ERCP and brushings is performed, suggesting than EUSFNA is not a risk factor for peritoneal seeding. ${ }^{56}$ The use of FNB can help by providing tissue architectural information and allow immunohistochemical stains. ${ }^{52}$ Guidelines of European society of Gastrointestinal Endoscopy (ESGE) and American Gastroenterological Association (AGA) recommend the use of a $25 \mathrm{G}$ or $22 \mathrm{G}$ FNA or FNB needle for routine EUS guided sampling of pancreatic masses. ${ }^{52,57}$ Rapid on-site cytologic evaluation (ROSE) can also increase the diagnostic yield up to $20 \%$ and decrease inadequate samples and the number of passes necessary to establish the diagnosis. Nevertheless, ROSE is not always available, increases the time procedure and also the costs; therefore it is not recommended according to the ESGE guidelines. ${ }^{52}$ Furthermore, cytology specimens can be obtained at the time of biliary decompression during ERCP. Brush cytology sensitivity ranges from 30 to $60 \%$ with a high positive predictive value (PPV) but a low negative predictive value (NPV) ${ }^{58,59} \mathrm{In}$ addition to brush cytology alone, forceps biopsy under fluoroscopic control may help to increase the diagnostic yield. ${ }^{59}$ In a prospective single-blind comparative study on 51 patients comparing EUS-FNA vs biliary brush cytology and intraductal forceps biopsy, EUS-FNA was superior to ERCP samples in pancreatic cancers. ${ }^{60}$

\section{Cholangiocarcinoma}

dCCA should be suspected based on clinical findings as right-upper-quadrant abdominal pain and features of biliary obstruction. Cholangitis is an unusual presentation. Although TUS and CT-scan may suggest CCA, MRI is the preferred modality for the extent of the disease: T2-weighted imaging sequences that display fluid as high signal intensity may define the level of a biliary stricture and identify malignant features such as a stricture of more than $1 \mathrm{~cm}$ of length, irregular margins, and shouldering (Figure 3). ${ }^{61}$ MRI has a sensitivity of $77 \%$ to $86 \%$ with a specificity of $63 \%$ to 98\%. ${ }^{62,63}$ ERCP has an important role in the diagnosis of dCCA as brushing and forceps biopsies can establish the diagnosis (Figure 3). The yield of brush cytology varies between $44-80 \%$ for CCA. ${ }^{64,65}$ Newer techniques such as digital image analysis (DIA) and fluorescence in situ hybridization (FISH) have been incorporated into the cytologic evaluation of bile duct brushings to enhance the sensitivity of cytology. ${ }^{66,67}$ In a study of Ponchon et al, combining brush 


\section{A}

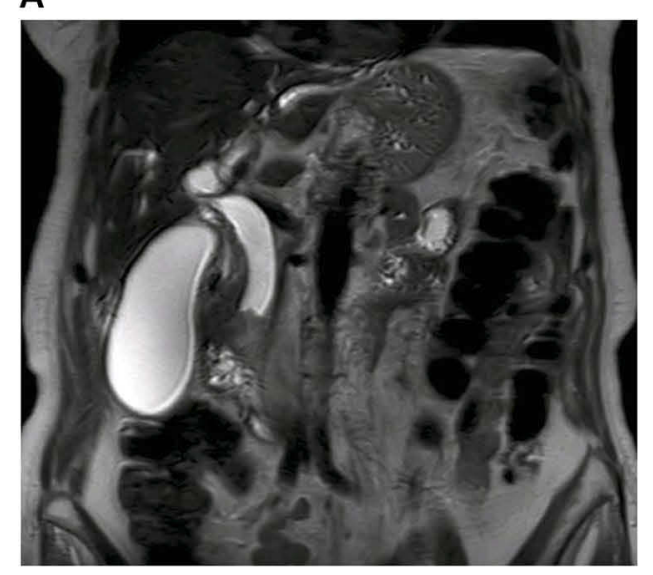

B

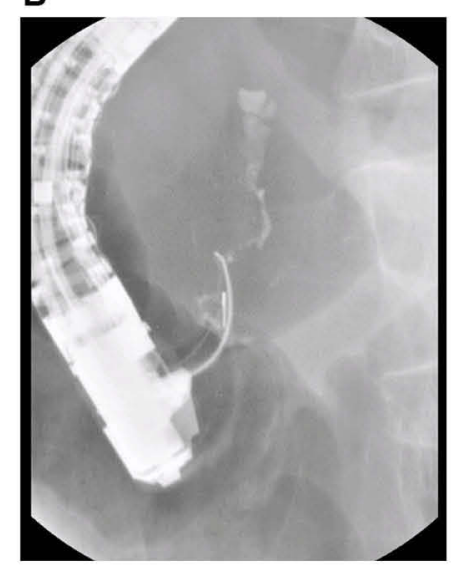

C

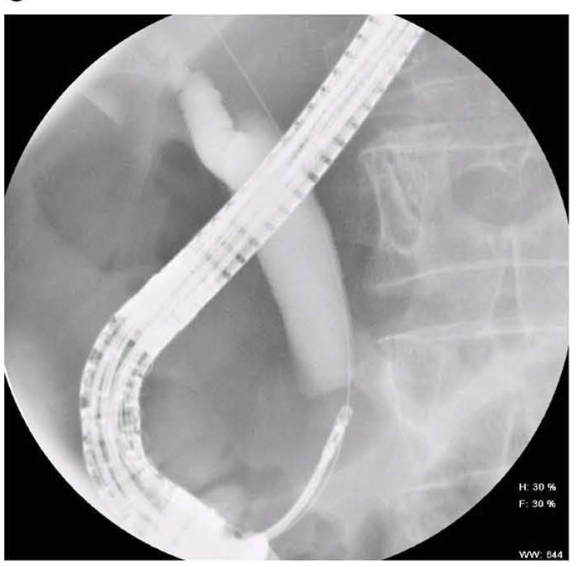

Figure 3 A 84-year-old woman presenting painless jaundice. TUS showed CBD and intrahepatic bile duct dilatation. MRI showed a suspected 22mm intraductal mass at the distal part of the CBD with an upstream dilatation (A). EUS-FNA confirmed an intraductal mass in the CBD suggestive of cholangiocarcinoma. ERCP revealed a long, irregular, distal biliary stricture (B); brushing and intraductal forceps biopsies confirmed the presence of malignant cells (C).

Abbreviations: TUS, transabdominal ultrasound; CBD, common bile duct; MRI, Magnetic resonance imaging; EUS-FNA, endoscopic ultrasound fine needle biopsy; ERCP, Endoscopic retrograde cholangiopancreatography.

cytology (43\% sensitivity) and intraductal biopsy (30\%), the cumulative yield reached $63 \% .{ }^{68}$ Nevertheless, a recent meta-analysis in which six studies provided data on the combination of brushing (sensitivity $45 \%$ ) and biopsy (sensitivity $48.1 \%$ ), showed a little improvement in sensitivity $(59.4 \%){ }^{58}$ The role of EUS is also important, with a high detection rate of tumor compared with CT-scan and MRI, and also in determining the extent of the disease and when sampling regional lymph node is needed. ${ }^{69}$ In a large single-center study of 228 patients with 81 CCA (51 dCCA), EUS detected the tumor in $100 \%$ of patients with dCCA. The sensitivity of EUS-guided FNA was significantly higher in distal than in proximal CCA ( $81 \%$ vs $59 \%$, respectively). ${ }^{70}$ In the study of Weilert, evaluating EUS-FNA vs ERCP for the diagnosis of malignant biliary strictures, the sentivity of both techniques were similar (79\%) in patients with dCCA. ${ }^{60}$ Finally, EUS-FNA has a well-established sensitivity between $85 \%$ to $93 \%$ in recent studies ${ }^{53,69,71}$ and maintains a high diagnostic yield even in patients with no identifiable mass on previous imaging (sensitivity:73-89\%). ${ }^{60,69,71}$

\section{Gallbladder Adenocarcinoma}

GB adenocarcinoma is usually identified on CT-scan as infiltration or a polypoid mass or a thickening of the GB wall. The T staging accuracy of CT reached 71 to $86 \%{ }^{24}$ The sensitivity of MRI to detect nodal invasion ranges between $56 \%$ and $92 \%$ and $67-100 \%$ to determine local invasion $^{24}$ EUS also has a growing role in the diagnosis and staging. EUS-FNA can also be used for the diagnosis and has a sensitivity of $80 \%$ and a specificity of $100 \%{ }^{24}$

\section{Metastases}

Multiples digestive and non-digestive cancers can metastasize, extrinsically by a lymph node or intrinsically within the bile duct. These are, in order of frequency: gastric, colon, breast, lung, renal cell carcinoma, melanoma, and hepatocellular cancer. Malignant lymphadenopathy is an infrequently cause of MDBO. ${ }^{24}$

\section{Differential Diagnosis Of Malignant Versus Benign Strictures}

Differentiating pancreatic adenocarcinoma with auto-immune pancreatitis (AIP) may be challenging as AIP can mimic pancreatic cancer when it presents as a focal inflammatory mass. ${ }^{72}$ An increased serum Ig-G4 level (2X the normal range) will be in favor of AIP although it can also be increased in pancreatic cancer. ${ }^{73}$ To note, CA $19-9$ can also be elevated in AIP. ${ }^{73}$ Imaging technique (MRI), as well as biopsies of the papilla and EUS-FNA/FNB of the pancreatic mass revealing a lymphoplasmacytic infiltrate rich in $\mathrm{IgG} 4$ can lead to the correct diagnosis. ${ }^{74}$ AIP can also involve other organs, as the biliary tract, kidneys or retroperitoneum. ${ }^{74}$ Steroid test can also allow differentiating AIP versus pancreatic tumor as AIP is steroid-sensitive. ${ }^{74} \mathrm{MDBO}$ can also be seen in patients with chronic pancreatitis due to recurrent inflammation of the head of the pancreas leading to parenchymal fibrosis. Sometimes, imaging techniques as CT, MRI or EUS cannot easily differentiate between pancreatic cancer or CP. EUSFNA will be crucial for the therapeutic management. ${ }^{72}$ Similarly, the differential diagnosis between benign inflammatory cholangiopathies (such as PSC, HIV-related 
cholangiopathy, eosinophilic and IgG4 related cholangitis) and CCA can be challenging (Table 1$)^{72}$

\section{Advanced Endoscopic Diagnosis}

In suspected MDBO, based on clinical, imaging or endoscopic (ERCP, EUS) modalities with inconclusive histopathological confirmation obtained by standard techniques such as FNA/FNB samples or biliary brushings and forceps biopsies, novel techniques such cholangioscopy, intraductal ultrasonography (IDUS) or Confocal Laser Endomicroscopy (CLE) have been developed. These invasive endoscopic procedures are not used routinely and are not largely available, but can be performed during ERCP.

Cholangioscopy allows direct visualization of the biliary tree. Historically, it was performed with a dual-operator reusable baby endoscope passed through a mother therapeutic duodenoscope. Recently, a single-operator single-use cholangiopancreatoscope (SOCP) was developed, firstly with a fibro-optic based device (FSOCP) and then a digital version (DSOCP). Furthermore, direct peroral cholangioscopy system using an ultraslim endoscope advancing directly in the ductal system has emerged. ${ }^{75}$ Direct visualization of the biliary tree is useful to distinguish benign and malignant conditions based on the evaluation of the vascular pattern such as irregular, tortuous vessels (PPV 100\%), or the presence of nodularity, papillary characteristics and irregular surface. ${ }^{76-78}$ A recent study of Mizrahi et al showed that the visual diagnostic yield of DSOCP was higher than FSOCP $(73 \%$ vs $37 \%$, $\mathrm{p}=0.004){ }^{79}$ Furthermore, cholangioscopy-guided biopsies with dedicated forceps allow targeted tissue sampling. ${ }^{75} \mathrm{~A}$ recent review reported studies using FSOCP with a sensitivity of $49 \%$ to $100 \%$, a specificity of $82 \%$ to $100 \%$ and diagnostic accuracy of $55 \%$ to $100 \%{ }^{75}$ Two studies using DSOCP reported sensitivities of $85 \%$ and $57 \%$ and specificities of $100 \%{ }^{80,81}$

IDUS involves a radial ultrasound probe being introduced through the duodenoscope on a guidewire during ERCP. IDUS characteristics of malignant strictures include hypoechoic asymmetric wall thickening, irregular borders and abrupt shoulders. ${ }^{82}$ IDUS is useful in defining a longitudinal extent and invasion of other structures. (pancreatic parenchyma, portal vein, right hepatic artery). ${ }^{83}$ Studies showed a good sensitivity and specificity $(98 \%)^{84}$ and a meta-analysis of 5 studies showed an IDUS accuracy for malignant obstructions reaching $84 \%-95 \% .{ }^{83}$ Compared to ERCP and MRCP, Domagk and colleagues demonstrated that the combination of ERPC and IDUS correctly diagnosed malignancy in $88 \%$ (vs $76 \%$ and $58 \%$ ). ${ }^{26}$ In term of staging, IDUS showed a low accuracy in nodal evaluation (69\%), possibly due to a limited depth of ultrasonic penetration. ${ }^{83}$

CLE is performed with a reusable miniprobe, which is also passed through the duodenoscope in the lumen of an ERCP catheter. After administration of $2.5 \mathrm{ml}$ to $5 \mathrm{ml}$ of $10 \%$ intravenous fluorescein dye, it produces live highresolution images of the biliary epithelium. Nevertheless, it is an expensive technique and not readily available. ${ }^{83}$

\section{Clinical Practice: A Proposed Diagnostic Algorithm}

The first step in the management of MDBO is to establish the diagnosis and identify the stage of the disease. According to the availability of imaging modalities, CT-scan and/or MRI are the two main imaging techniques to assess tumor extension, establish vascular involvement and the presence or the absence of metastases. The second step will focus on obtaining tissue samples to confirm the diagnosis:

- EUS-FNA if a mass is identified as well as surrounding lymph nodes or identified metastases (ex in the left liver or the peritoneum).

- ERCP with biliary brushings and forceps biopsies, if no mass is identified

These two steps aim to identify patients with a resectable disease that can benefit from surgery from the outset of those who will need a neoadjuvant treatment for a downstaging or a palliative treatment in patients with advanced disease.

A practical algorithm for the management of patients with suspected MDBO, according to previously published reviews $^{4,85}$ is proposed in Figure 4

\section{Endoscopic Management Patients With Resectable Cancer: Preoperative Biliary Drainage Indications}

Preoperative biliary drainage (PBD) in patients with $\mathrm{MDBO}$ is an area of controversy. Previously studies suggested that hyperbilirubinemia was associated with increased postoperative morbidity and mortality, and therefore advocated PBD. ${ }^{86}$ Nevertheless, in 2010, a large randomized control trial (RCT) comparing PBD vs no PBD (202 patients with MDBO) reported higher rates of severe complications in patients undergoing PBD (74\%vs 39\%). ${ }^{87}$ No improvement 


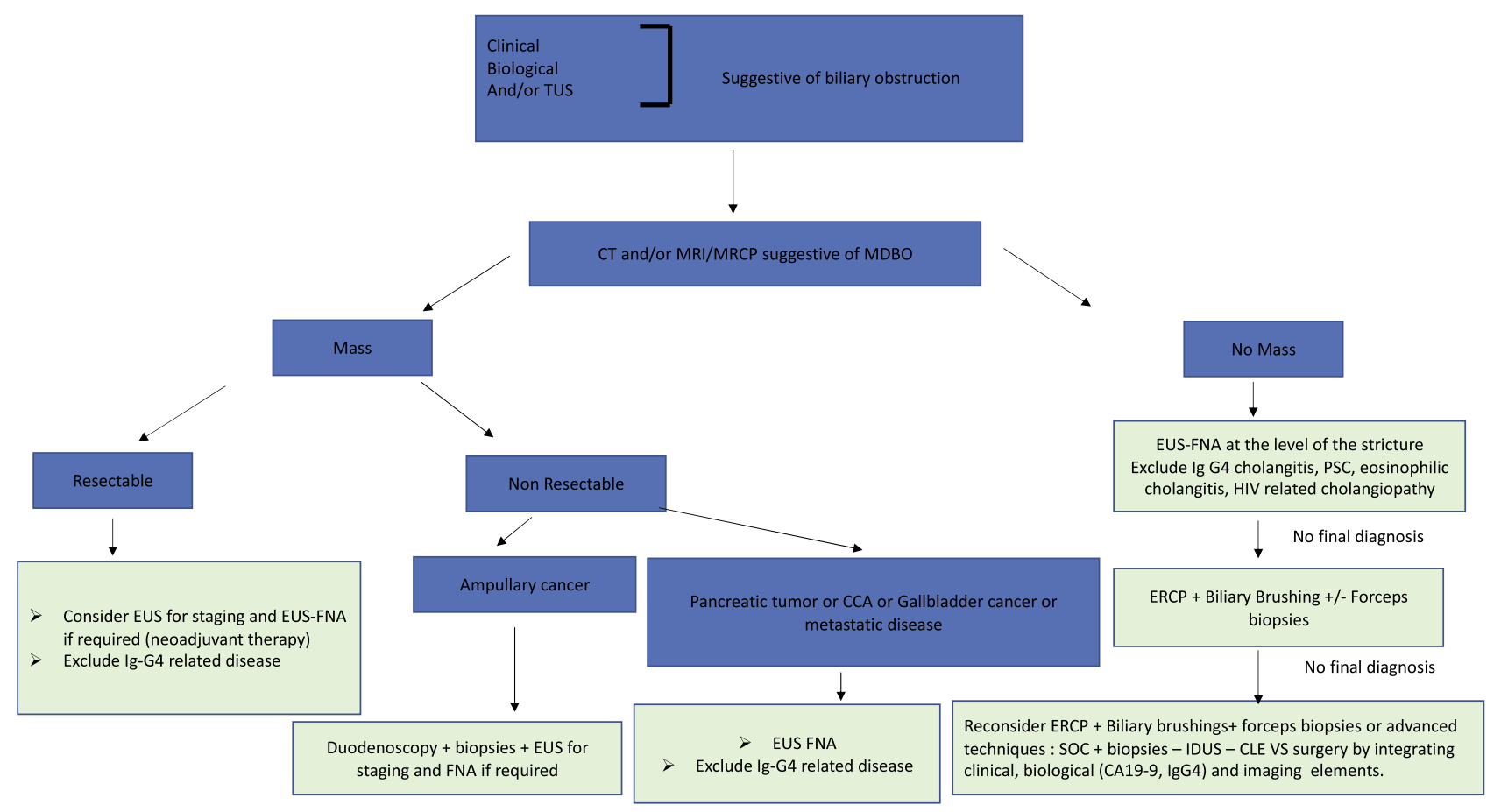

Figure 4 Algorithm for the assessment of patients with biliary obstruction.

Abbreviations: TUS, transabdominal ultrasonography; CT, computed tomography; MRI, Magnetic resonance imaging; MDBO, malignant distal biliary obstruction; EUS, endoscopic ultrasound; FNA, fine needle aspiration; CCA, cholangiocarcinoma; PSC, primary sclerosing cholangitis; SOC, single-operator-cholangioscopy; IDUS, intraductal ultrasonography; CLE, confocal laser endomicroscopy; CA 19-9, Carbohydrate antigen 19-9.

in any outcome was observed in the PBD group..$^{87}$ Of note, in the aforementioned study, the PBD group underwent surgery within 4-6 weeks and one single plastic stent (PS) was used, which could contribute to the high complication rate related to $\mathrm{PBD}^{87}$ Since then, numerous studies and meta-analysis have been published; the latest meta-analysis including 32 studies with patient with MBDO due to pancreatic cancer, suggested that refraining from PBD could be associated with a better outcome. ${ }^{88}$ Subsequently, the current guidelines published by the ESGE recommend against routine PBD in patient with extra-hepatic obstruction. ${ }^{89}$ Well-accepted indications for PBD are cholangitis or intractable pruritus. ${ }^{89}$ Severe jaundice was also advocated as an indication of biliary drainage: Sauvanet et al have recently published in a retrospective series of 1200 patients a high risk of severe postoperative in patients with severe jaundice (total serum bilirubin $>300 \mu \mathrm{mol} / \mathrm{l}$ ). ${ }^{90}$ In controversy, Arkadopoulos et al showed in a retrospective study of 152 patients that even in patients with total serum bilirubin $>256 \mu \mathrm{mol} / \mathrm{l}$, PBD presented no advantage. ${ }^{91}$ Of note, patients with total serum bilirubin $>250 \mu \mathrm{mol} / 1$ were excluded from the largest RCT of PBD vs no $\mathrm{PBD}^{87}$ Therefore, the indication of severe jaundice remains unclear. The current guidelines of ESGE also recommend
PBD in case of delayed surgery (more 2 weeks), and in patients undergoing neoadjuvant chemotherapy who also benefit PBD to bring liver functions tests to ranges acceptable for chemotherapy and avoid potential hepatotoxic effects of chemotherapeutic drugs (Figure 5). ${ }^{89}$

\section{Route}

The endoscopic route is preferred over the percutaneous route (PTC) ${ }^{89}$ PTC has higher morbidity due to the risk of puncture-related hemorrhage, cutaneous infection, and catheter tract recurrence. ${ }^{89}$ Percutaneous tract seeding is a major concern and can compromise potentially curable cases $(5,2 \%){ }^{92}$ Data from 3 retrospective studies showed longer patient survival and less frequent peritoneal or liver recurrence in the endoscopic group. ${ }^{93-95}$

\section{Which Type Of Stent?}

The current ESGE guidelines recommend the placement of a $10 \mathrm{~mm}$ diameter self-expandable metal stent (SEMS) for PBD $^{89}$ (Figure 5). A meta-analysis including of 5 studies (4 retrospective and 1 prospective, 704 patients) demonstrate that SEMS have lower rate of endoscopic reintervention compared to PS (3.4 vs $14.8 \%$ ) and no difference in overall surgical or morbidity or mortality. ${ }^{96} \mathrm{~A}$ recent RCT of 86 patients comparing PS vs fully covered metallic stent (FCSEMS) showed 


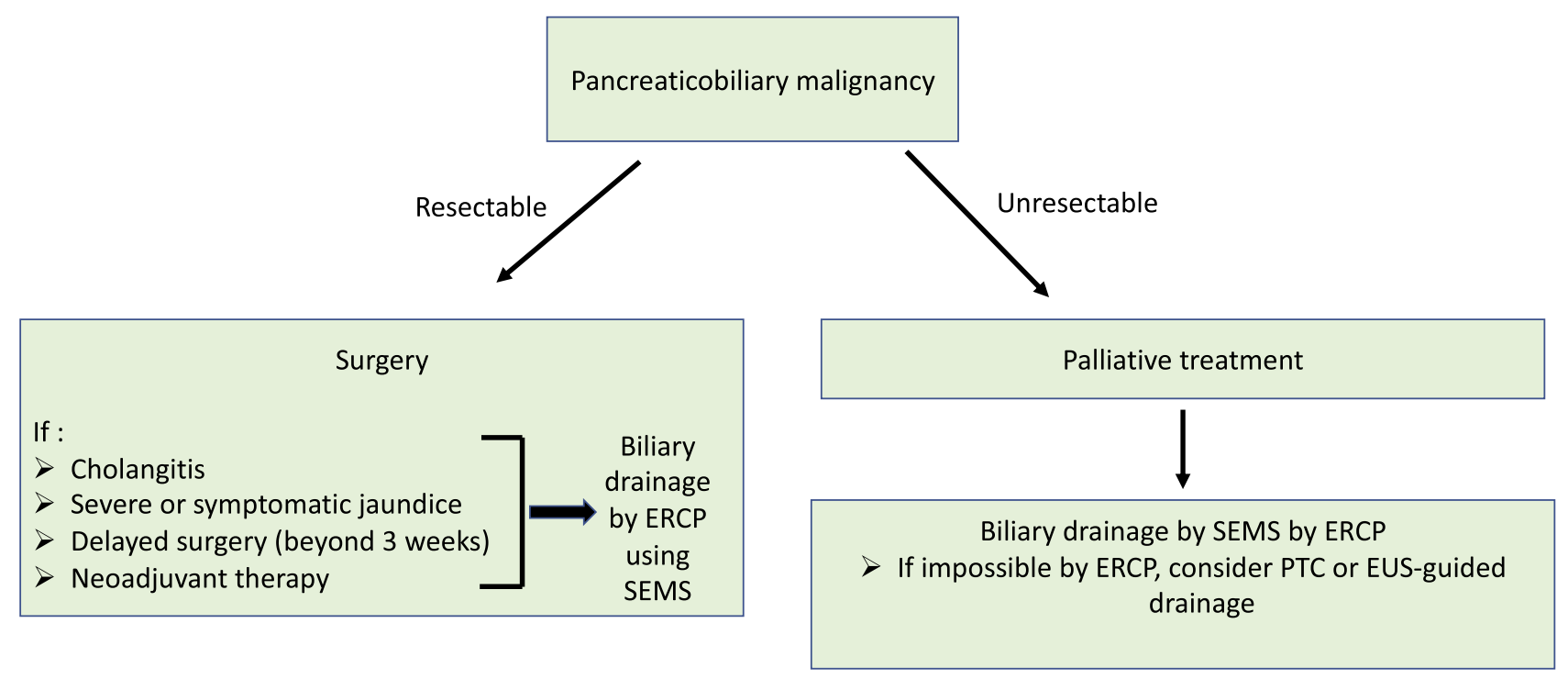

Figure 5 Algorithm for the endoscopic management of patients with confirmed pancreaticobiliary malignancy.

Abbreviations: ERCP, Endoscopic retrograde cholangiopancreatography; SEMS, self-expandable metal stents; PTC, percutaneous cholangiography; EUS, endoscopic ultrasound.

similar outcomes (need for reintervention, surgery-related AE and mortality). Of note, in this study, the delay between drainage and surgery was only 13 days. ${ }^{97}$ Tol et al also showed that FCSEMS yields a better outcome compared with PS for PBD in pancreatic cancer. ${ }^{98}$ In the setting of neoadjuvant therapy, SEMS were shown to be better than PS: an RCT of 54 patients showed that FCSEMS had a longer stent patency duration and fewer days of delay in chemotherapy treatment compared to plastic and uncovered SEMS (USEMS); total costs were the same in both groups. ${ }^{99}$ Similarly, two retrospective studies showed that PS have more complications than SEMS; ${ }^{100,101}$ with SEMS, the delay before neoadjuvant treatment was shorter and the costs were similar; the type of SEMS was specified in only 1 of these studies and were FCSEMS ${ }^{101}$ FCSEMS also has the advantage of being removable if surgery is not performed. A recently published multicenter RCT of 119 patients comparing FCSEMS and USEMS in pancreatic cancer showed an equal, sustained biliary drainage $(72.2 \%$ vs $72.9 \%)^{102}$ Tumor ingrowth was observed in 0 vs $16.7 \%$ (p $<0.01)$ and stent migration in 6 vs $0 \%(\mathrm{p}=0.03)$. Acute cholecystitis did not differ significantly between the two groups (9.3\% (4/43) for FCSEMS vs 4.8\% (2/42) for USEMS, $\mathrm{p}=0.08$ ). Finally, the only predictors of failure to decompress biliary obstruction were SEMS of $4 \mathrm{~cm}$ length compared to 6and 8-mm length and the presence of gallbladder. ${ }^{102}$ Of note, SEMS does not compromise $\mathrm{R} 0$ resection or increases the risk of unresectability, in a retrospective study of 593 patients. ${ }^{103}$

\section{Unresectable Cases}

\section{Palliative Biliary Drainage}

Indications

The majority (70\%) of MDBO are unresectable at the time of the presentation. Furthermore, MDBO is often associated with recurrent cholangitis, symptoms of pruritus, loss of appetite, nausea, delayed wound healing and renal failure. In this setting, palliative biliary stenting relieves symptoms and improve quality of life. ${ }^{104}$

\section{Route and type of stents}

The ESGE guidelines recommend biliary drainage by ERCP as the 1st route of choice, rather than surgery or the percutaneous route (Figure 5). ${ }^{89}$ Indeed, surgical bypass showed low rates of recurrent jaundice (2-5\%) but with significant postoperative morbidity and mortality, in up to $25 \%$ in some series. ${ }^{105,106}$ Three meta-analyses comparing primary biliary stenting vs surgical bilio-digestive anastomosis demonstrated more procedure-related complications as well as the 30-day mortality in the surgery group $\left(16.3 \%\right.$ vs $9.6 \%$ stated by Lima et al). ${ }^{107-109}$ There was no difference regarding the success of the procedures in both groups. Based on the current data, biliary stenting through ERCP is also preferred over PTC because of an overall lower rate of adverse events ( $8.6 \mathrm{vs}$ $12.3 \%$ ), fewer repeat procedures, shorter hospitalization, lower costs and the lack of external drainage catheters. ${ }^{110}$ 
EUS-guided biliary drainage has emerged as a useful tool in pancreatobiliary therapeutic management but should be performed in cases where biliary drainage by standard ERCP techniques has failed. ${ }^{89}$ Concerning the type of stents, current data recommend SEMS insertion for palliative drainage ${ }^{89}$ According to the 5 meta-analyses comparing SEMS with PS for the endoscopic drainage of MDBO, SEMS are preferred over PS. ${ }^{111-115}$ SEMS are associated in longer stent patency, lower complication rates, fewer reinterventions and longer patient survival. ${ }^{112}$ Moreover in term of quality of life, SEMS have better scores over PS. ${ }^{116}$ Although SEMS are more expensive than PS, no significant difference in costs have been observed in the long-term period. ${ }^{117}$ The most recent RCT has also shown no difference in total costs for SEMS and PS in patients with short-time survival $(<3)$ months or with metastatic disease. ${ }^{117}$ The choice of using covered SEMS (CSEMS) over USEMS for palliation of MDBO remains controversial. Although CSEMS were developed in an attempt to prolong stent patency, this has not been definitively demonstrated ${ }^{89}$ USEMS have a high risk of stent occlusion due to tumor ingrowth through the metal mesh. On the other hand, CSEMS have lower tissue ingrowth, but higher migration rates and tissue overgrowth as compared to USEMS. $^{89}$ Eight meta-analyses assessed the use of CSEMS vs USEMS. ${ }^{118-125}$ None of them have demonstrated a significant difference concerning the clinical outcomes. The most recent one published in 2018 by Tringali et al showed that there was no statistically significant difference for either stent or patient survival between CSEMS and USEMS in patients with MBDO. Nevertheless, they report a stent failure rate reduction of $32 \%$, suggesting a possible benefit of CSEMS, at the expense of a higher risk of migration. ${ }^{125}$ Controversially, in a recent RCT published by Conio and al. ${ }^{126}$ on 148 patients, comparing a same self-conformable USEMS and FCSEMS, FCSEMS had lower stent patency (240 days vs 541 days for USEMS, $\mathrm{p}=0.031$ ). FCSEMS presented more stent-adverse events as measured by stent dysfunction (overall adverse events were 26.4\% for FCSEMS vs $13.2 \%$ for USEMS, although not statistically significant). FCSEMS dysfunction included migration (5/78 of patients) and early occlusion, mainly due to sludge (8/78) and overgrowth (4/78). On the other hand, USEMS had more ingrowth tumor $(13.2 \%$ vs $0 \%$ in FCSEMS, $\mathrm{p}=0.001)$. With respect to cholecystitis after insertion of a FCSEMS, four meta-analysis reported this outcome and none of these have reported a higher risk of cholecystitis in the covered group. ${ }^{120-123}$ To prevent this complication, some authors advise the placement of the covered part below the level of the cystic duct. Similar to the previous meta-analyses, Tringali et al did not show differences in pancreatitis rate between FCSEMS and USEMS ${ }^{125}$ To summarize, currently, there is no consensus regarding the choice of covered vs uncovered, each of them having their advantages and inconveniences.

\section{Advances In Endoscopic Palliation}

\section{Endoscopic biliary palliation}

The main issue using stents is re-occlusion. To prolong the stent patency of SEMS, some strategies have been developed. The incorporation of a chemotherapeutic agent into the covering material of stent has been studied in animal studies and a small cohort of patients with MDBO: paclitaxel-eluting stent did not show more advantages compared to standard SEMS alone in an RCT of 72 patients $^{127}$ Antireflux covered SEMS designs have been investigated and seem to lead to longer patency. In the study of Lee et al, the overall reflux of barium on barium meal examination was $7.7 \%$ in the Anti-Reflux Valve Metal Stent group compared to $100 \%$ in the covered group $^{128}$ Nevertheless, more data are needed regarding the patient's outcome. Antimigration systems (flared ends and anchoring flaps) have also been developed with promising results. ${ }^{129,130}$

Endoscopic ultrasonography-guided biliary drainage (EUS-BD) In expert centers, EUS-BD is an evolving method for biliary drainage in patients with $\mathrm{MDBO}$ in whom standard ERCP failed. Compared to PTC, EUS-BD is similarly effective but associated with a lower rate of adverse events and fewer re-interventions. ${ }^{131}$ The different techniques include EUS-guided ductal access with a guidewire that is retrieved by a duodenoscope for biliary interventions (rendez-vous technique) or the creation of nonanatomic direct access connecting the biliary tree with the stomach (hepaticogastrostomy [HG]) or the duodenum (choledochoduodenostomy [CD]). The rendez-vous maneuver is generally attempted first if the papilla is accessible because it provides an anatomic pathway for drainage with transpapillary biliary stent placement. However, the rendezvous maneuver can fail because of an inaccessible papilla (altered anatomy, duodenal obstruction, gastric outlet syndrome or the presence of enteral stents) or a failure to advance the wire through a stricture. In these patients, $\mathrm{HG}$ or $\mathrm{CD}$ are feasible drainage techniques. ${ }^{132}$ Four meta- 
analyses reported that EUS-BD was clinically successful in $87-94 \%$ of cases with adverse events reported in $16-29 \%{ }^{133,134}$ Recently, EUS-BD as emerged as firstline therapy in malignant biliary decompression. To date, 3 RCT's comparing EUS-BD (HG and or CD) with ERCP as a primary modality for biliary drainage with $\mathrm{MBO}$ have been published. ${ }^{135-137}$ Technical success for EUS-BD ranges between $91-94 \%{ }^{135,136}$ In two of these trials, clinical success and adverse events were similar for both technique $^{136,137}$ whereas, in Paik et al trial ${ }^{135}$ EUS-BD was superior to ERCP with longer stent patency, lower adverse events rate and fewer re-interventions. More studies are needed to confirm these results.

Radiofrequency ablation (RFA)/photodynamic therapy (PDT) RFA and PDT are the main novel modalities in palliative MBO. RFA acts by delivering thermal energy within the tissue leading to necrosis and cellular deaths. ${ }^{138}$ Recently, a biliary catheter that can be introduced on a guidewire has been developed and used to ablate unresectable lesions before stent placement during ERCP (PS and SEMS). Several studies have been published so far with an excellent clinical outcome and possible improvement of survival. ${ }^{138-140}$ The clinical value of biliary RFA has been confirmed in a meta-analysis of 9 studies including 505 patients with MDBO in whom biliary stenting with SEMS was performed with or without prior RFA application via the endoscopic or the percutaneous routes. In the group RFA, significantly longer stent patency ( 50 vs 37 days, $\mathrm{p}<0.002$ ) and survival ( 285 vs 248 days, $\mathrm{p}<0.001$ ) were observed. Abdominal pain was the only AE that was more demonstrated in the RFA group. ${ }^{141}$ Additional techniques include photodynamic therapy (PDT), which requires the injection of an intravenous porphyrin photosensitizing agent followed by the endoscopic application of a specific wavelength of light to the tumor bed. Several studies have demonstrated benefits of PDT. ${ }^{142,143}$ Possible adverse events are light sensitivity, cholangitis, and liver abscess. ${ }^{144}$

\section{Particular Cases}

Drainage Of Suspected Malignant Biliary Obstruction In the case of extrahepatic biliary of unconfirmed etiology, current guidelines recommend against the use of USEMS as they are known to have poor long-term patency in benign disease and are difficult or impossible to remove. ${ }^{89}$

\section{Malignant Bilioduodenal Obstruction}

Nowadays, no study has compared the endoscopic vs surgical approach for combined bilioduodenal obstruction. ESGE guidelines suggest inserting a biliary SEMS and an uncovered duodenal SEMS in those patients. ${ }^{89}$

\section{Stent Dysfunction}

According to ESGE guidelines, in case of non-functional SEMS, a plastic stent or a new SEMS should be placed within the original stent. ${ }^{89}$

\section{Peri-Procedural And Technical Aspects Acute Pancreatitis Prophylaxis}

In patients with no contra-indications, $100 \mathrm{mg}$ of intrarectal diclofenac or indomethacin should be routinely administrated to prevent post ERCP pancreatitis. ${ }^{89}$

\section{Antibioprophylaxy}

Antibioprophylaxy should be administrated before ERCP in selected patients such as immunosuppression or patients with an expected incomplete biliary drainage ${ }^{89}$

\section{Biliary Sphincterotomy Before Stent Insertion?}

Two meta-analysis assessed the utility to perform systematically biliary sphincterotomy before stenting. ${ }^{145,146}$ One (3RCT's, 338 patients) was associated with a reduced risk of post ERCP acute pancreatitis when sphincterotomy was performed, but an increased risk of bleeding. ${ }^{145}$ The second one (5 RCT's, 12 comparative studies, 2710 patients) did not show an increased risk of post ERCP acute pancreatitis, stent migration or occlusion in the sphincterotomy group but confirmed a higher risk of bleeding. ${ }^{146}$ Even in the subgroup analysis of patients with SEMS, the rate of post ERCP acute pancreatitis was not increased. Concerning FCSEMS, a hypothesis is that their coverage could obstruct the pancreatic outflow, leading to a high incidence of postERCP acute pancreatitis. For this question, current ESGE guidelines, suggest against systematic biliary sphincterotomy before the placement of a PS or SEMS. $^{89}$

\section{Conclusion}

Despite recent advances, MDBO remains a clinical challenge. Both correct diagnosis and appropriate therapeutic management require a multidisciplinary approach. Combination of clinical and biological parameters, imaging and endoscopic features, as well as histopathology 
through tissue sampling, will offer insight for defining the underlying cause. The development of cholangioscopy is promising, with the possibility of targeted biopsies in case of failure of standard techniques. Furthermore, endoscopy is the corner stone in the treatment of these patients, providing PBD in selected cases with resectable disease, as well as palliative biliary drainage. In case of PBD, FCSEMS seem to be the best choice, compared to PS. Regarding palliation, the choice between USEMS versus CSEMS is still debated, each type of stents having its own advantages and drawbacks. Finally, EUS-guided biliary drainage, although not as first line therapy, is continually growing.

\section{Abbreviations}

MDBO, malignant distal biliary obstruction; CCA, cholangiocarcinoma; GB, gallbladder; dCCA, distal cholangiocarcinoma; ALP, alkaline phosphatases; GGT, gamma glutamyl transferase; ALT, alanine aminotransferase; AST, aspartate aminotransferase; CA 19-9, Carbohydrate antigen 19-9; CEA, carcinoembryonic antigen; TUS, transabdominal ultrasonography; CT, computed tomography; MRI, magnetic resonance imaging; MRCP, magnetic resonance cholangiopancreatography; EGD, esophagogastroduodenoscopy; ERCP, endoscopic retrograde cholangiopancreatography; EUS, endoscopic ultrasound; FNA, fine-needle aspiration; PET/CT, positron emission tomography/computed tomography; CE EUS, contrast-enhanced endoscopic ultrasound; FNB, fine needle-biopsy; ESGE, European society of gastrointestinal endoscopy; AGA, American gastroenterological association; PPV, positive predictive value; NPV, negative predictive value; IDUS, intraductal ultrasonography; CLE, confocal laser endomicroscopy; SOCP, single operator cholangiopancreatoscopy; FSOCP, fibro-optic single operator cholangiopancreatoscopy; DSOCP, Digital single operator cholangiopancreatoscopy; DPCS, Direct peroral cholangioscopy system; PBD, preoperative biliary drainage; RCT, randomized control study; SEMS, self-expandable metal stent; PS, plastic stent; FCSEMS, fully covered self-expandable metal stent; USEMS, uncovered self-expandable metal stent; PTC, percutaneous cholangiography; EUS-BD, endoscopic ultrasound - biliary drainage; HG, hepaticogastrostomy; CD, choledochoduodenostomy; RFA, radiofrequency ablation; PDT, photodynamic therapy.

\section{Disclosure}

The authors report no conflicts of interest in this work.

\section{References}

1. Boulay BR, Birg A. Malignant biliary obstruction: from palliation to treatment. World J Gastrointest Oncol. 2016;8(6):498-508. doi:10.4251/wjgo.v8.i6.498

2. Fogel EL, Shahda S, Sandrasegaran K, et al. A multidisciplinary approach to pancreas cancer in 2016: a review. Am J Gastroenterol. 2017;112(4):537-554. doi:10.1038/ajg.2016.610

3. Pu LZCT, Singh R, Loong CK, de Moura EGH. Malignant biliary obstruction: evidence for best practice. Gastroenterol Res Pract. 2016;2016:1-7. doi:10.1155/2016/3296801

4. Singh A, Gelrud A, Agarwal B. Biliary strictures: diagnostic considerations and approach. Gastroenterol Rep. 2015;3(1):22-31. doi:10.1093/gastro/gou072

5. Rahib L, Smith BD, Aizenberg R, Rosenzweig AB, Fleshman JM, Matrisian LM. Projecting cancer incidence and deaths to 2030: the unexpected Burden of thyroid, liver, and pancreas cancers in the United States. Cancer Res. 2014;74(11):2913-2921. doi:10.1158/ 0008-5472.CAN-14-0155

6. Hidalgo M. Pancreatic Cancer. N Engl J Med. 2010;362(17):16051617. doi:10.1056/NEJMra0901557

7. Rizvi S, Khan SA, Hallemeier CL, Kelley RK, Gores GJ. Cholangiocarcinoma - evolving concepts and therapeutic strategies. Nat Rev Clin Oncol. 2018;15(2):95-111. doi:10.1038/ nrclinonc.2017.157

8. Choi BI, Han JK, Hong ST, Lee KH. Clonorchiasis and cholangiocarcinoma: etiologic relationship and imaging diagnosis. Clin Microbiol Rev. 2004;17(3):540-552. doi:10.1128/CMR.17.3.540552.2004

9. Shaib Y, El-Serag HB. The epidemiology of cholangiocarcinoma Semin Liver Dis. 2004;24(2):115-125. doi:10.1055/s-2004-828889

10. Hundal R, Shaffer EA. Gallbladder cancer: epidemiology and outcome. Clin Epidemiol. 2014;6:99-109. doi:10.2147/CLEP.S37357

11. Sharma A, Sharma KL, Gupta A, Yadav A, Kumar A. Gallbladder cancer epidemiology, pathogenesis and molecular genetics: recent update. World J Gastroenterol. 2017;23(22):3978-3998. doi:10.3748/wjg.v23.i22.3978

12. Duffy A, Capanu M, Abou-Alfa GK, et al. Gallbladder cancer (GBC): 10-year experience at Memorial Sloan-Kettering Cancer Centre (MSKCC). J Surg Oncol. 2008;98(7):485-489. doi:10. 1002/jso.v98:7

13. Ahn DH, Bekaii-Saab T. Ampullary cancer: an overview HHS public access. Am Soc Clin Oncol Educ B. 2014;112-115. doi:10.14694/EdBook_AM.2014.34.112

14. Porta M, Fabregat X, Malats N, et al. Exocrine pancreatic cancer: symptoms at presentation and their relation to tumour site and stage. Clin Transl Oncol. 2005;7(5):189-197. doi:10.1007/BF02712816

15. Furukawa H, Okada S, Saisho H, et al. Clinicopathologic features of small pancreatic adenocarcinoma. A collective study. Cancer. 1996;78(5):986-990. doi:10.1002/(SICI)1097-0142(19960901) 78:5<986::AID-CNCR7>3.0.CO;2-A

16. Khan SA, Davidson BR, Goldin RD, et al. Guidelines for the diagnosis and treatment of cholangiocarcinoma: an update. Gut. 2012;61(12):1657-1669. doi:10.1136/gutjnl-2011-301748

17. Garcea G, Ngu W, Neal CP, Dennison AR, Berry DP. Bilirubin levels predict malignancy in patients with obstructive jaundice. $H P B$. 2011;13(6):426-430. doi:10.1111/j.1477-2574.2011.00312.x

18. Thomasset SC, Saunders D, Holland A, Dennison AR, Garcea G. Malignant biliary strictures in patients with a normal bilirubin and/ or normal liver enzymes. HPB (Oxford). 2015;17(11):969-974 doi:10.1111/hpb.12468

19. Kim HJ, Kim MH, Myung SJ, et al. A new strategy for the application of CA19-9 in the differentiation of pancreaticobiliary cancer: analysis using a receiver operating characteristic curve. $\mathrm{Am}$ $J$ Gastroenterol. 1999;94(7):1941-1946. doi:10.1111/j.15720241.1999.01234.x 
20. Nehls O, Gregor M, Serum KB. Bile Markers for Cholangiocarcinoma. Semin Liver Dis. 2004;24(02):139-154. doi:10.1055/s-2004-828891

21. Marrelli D, Caruso S, Pedrazzani C, et al. CA19-9 serum levels in obstructive jaundice: clinical value in benign and malignant conditions. Am J Surg. 2009;198(3):333-339. doi:10.1016/j.amjsurg.2008.12.031

22. Hasan S, Jacob R, Manne U, Paluri R. Advances in pancreatic cancer biomarkers. Oncol Rev. 2019;13(1):410. doi:10.4081/oncol.2019.410

23. Tsukada K, Takada T, Miyazaki M, et al. Diagnosis of biliary tract and ampullary carcinomas. J Hepatobiliary Pancreat Surg. 2008;15 (1):31-40. doi:10.1007/s00534-007-1278-6

24. Anderson MA, Appalaneni V, Ben-Menachem T, et al. The role of endoscopy in the evaluation and treatment of patients with biliary neoplasia. Gastrointest Endosc. 2013;77(2):167-174. doi:10.1016/j. gie.2012.09.029

25. Skordilis P, Mouzas IA, Dimoulios PD, Alexandrakis G, Moschandrea $\mathrm{J}$, Kouroumalis E. Is endosonography an effective method for detection and local staging of the ampullary carcinoma? A prospective study. BMC Surg. 2002;2:1. doi:10.1186/1471-2482-2-1

26. Domagk D, Wessling J, Reimer P, et al. Endoscopic retrograde cholangiopancreatography, intraductal ultrasonography, and magnetic resonance cholangiopancreatography in bile duct strictures: a prospective comparison of imaging diagnostics with histopathological correlation. Am J Gastroenterol. 2004;99(9):1684-1689. doi:10.1111/j.1572-0241.2004.30347.x

27. Ponchon T, Berger F, Chavaillon A, Bory R, Lambert R. Contribution of endoscopy to diagnosis and treatment of tumors of the ampulla of Vater. Cancer. 1989;64(1):161-167. doi:10.1002/(ISSN)1097-0142

28. Tse F, Barkun JS, Romagnuolo J, Friedman G, Bornstein JD, Barkun AN. Nonoperative imaging techniques in suspected biliary tract obstruction. HPB. 2006;8(6):409-425. doi:10.1080/ 13651820600746867

29. Tierney WM, Francis IR, Eckhauser F, Elta G, Nostrant TT, Scheiman JM. The accuracy of EUS and helical CT in the assessment of vascular invasion by peripapillary malignancy. Gastrointest Endosc. 2001;53(2):182-188. doi:10.1067/mge.2001.111776

30. Cannon ME, Carpenter SL, Elta GH, et al. EUS compared with CT, magnetic resonance imaging, and angiography and the influence of biliary stenting on staging accuracy of ampullary neoplasms. Gastrointest Endosc. 1999;50(1):27-33. doi:10.1016/S0016-5107(99) 70340-8

31. Ogura T, Hara K, Hijioka S, et al. Can endoscopic ultrasoundguided fine needle aspiration offer clinical benefit for tumors of the ampulla of vater? -An initial study. Endosopic Ultrasound. 2012;1(2):84. doi:10.7178/eus.02.006

32. DeFrain C, Chang CY, Srikureja W, Nguyen PT, Gu M. Cytologic features and diagnostic pitfalls of primary ampullary tumors by endoscopic ultrasound-guided fine-needle aspiration biopsy. Cancer. 2005;105(5):289-297. doi:10.1002/cncr.21306

33. Grossjohann HS, Rappeport ED, Jensen C, et al. Usefulness of contrastenhanced transabdominal ultrasound for tumor classification and tumor staging in the pancreatic head. Scand J Gastroenterol. 2010;45(78):917-924. doi:10.3109/00365521003702718

34. Brambs H-J, Claussen CD. Pancreatic and ampullary carcinoma. Ultrasound, computed tomography, magnetic resonance imaging and angiography. Endoscopy. 1993;25(01):58-68. doi:10.1055/s2007-1009126

35. Majumder S, Chubineh S, Birk J. Pancreatic cancer: an endoscopic perspective. Expert Rev Gastroenterol Hepatol. 2012;6(1):95-104. doi:10.1586/egh.11.93

36. Valls C, Andía E, Sanchez A, et al. Dual-phase helical CT of pancreatic adenocarcinoma. Am J Roentgenol. 2002;178(4):821826. doi:10.2214/ajr.178.4.1780821

37. Pietryga JA, Morgan DE. Imaging preoperatively for pancreatic adenocarcinoma. $J$ Gastrointest Oncol. 2015;6(4):343-357. doi:10.3978/j.issn.2078-6891.2015.024
38. Moutinho-Ribeiro P, Iglesias-Garcia J, Gaspar R, Macedo G. Early pancreatic cancer - the role of endoscopic ultrasound with or without tissue acquisition in diagnosis and staging. Dig Liver Dis. 2019;51(1):4-9. doi:10.1016/j.dld.2018.09.027

39. Fusari M, Maurea S, Imbriaco M, et al. Comparison between multislice CT and MR imaging in the diagnostic evaluation of patients with pancreatic masses. Radiol Med. 2010;115(3):453466. doi:10.1007/s11547-010-0490-7

40. Rao S-X, Zeng M-S, Cheng W-Z, Yao X-Z, Jin D-Y, Ji Y. Small solid tumors $(<$ or $=2 \mathrm{~cm})$ of the pancreas: relative accuracy and differentiation of $\mathrm{CT}$ and MR imaging. Hepatogastroenterology. 2011;58(107-108):996-1001.

41. Treadwell JR, Zafar HM, Mitchell MD, Tipton K, Teitelbaum U, Jue J. Imaging tests for the diagnosis and staging of pancreatic adenocarcinoma. Pancreas. 2016;45(6):789-795. doi:10.1097/ MPA.0000000000000524

42. Dewitt J, Devereaux BM, Lehman GA, Sherman S, Imperiale TF. Comparison of endoscopic ultrasound and computed tomography for the preoperative evaluation of pancreatic cancer: a systematic review. Clin Gastroenterol Hepatol. 2006;4(6):717-725. doi:10.1016/j. cgh.2006.02.020

43. Soriano A, Castells A, Ayuso C, et al. Preoperative staging and tumor resectability assessment of pancreatic cancer: prospective study comparing endoscopic ultrasonography, helical computed tomography, magnetic resonance imaging, and angiography. $\mathrm{Am}$ $J$ Gastroenterol. 2004;99(3):492-501. doi:10.1111/j.15720241.2004.04087.x

44. Chen J, Yang R, Lu Y, Xia Y, Zhou H. Diagnostic accuracy of endoscopic ultrasound-guided fine-needle aspiration for solid pancreatic lesion: a systematic review. J Cancer Res Clin Oncol. 2012;138(9):1433-1441. doi:10.1007/s00432-012-1268-1

45. Jafri M, Sachdev AH, Khanna L, Gress FG. The role of real time endoscopic ultrasound guided elastography for targeting EUS-FNA of suspicious pancreatic masses: a review of the literature and a single center experience. JOP. 2016;17(5):516-524.

46. Mei S, Wang M, Sun L. Contrast-enhanced EUS for differential diagnosis of pancreatic masses: a meta-analysis. Gastroenterol Res Pract. 2019;2019:1-9. doi:10.1155/2019/1670183

47. Inoue $\mathrm{K}$, Ohuchida $\mathrm{J}$, Ohtsuka $\mathrm{T}$, et al. Severe localized stenosis and marked dilatation of the main pancreatic duct are indicators of pancreatic cancer instead of chronic pancreatitis on endoscopic retrograde balloon pancreatography. Gastrointest Endosc. 2003;58 (4):510-515. doi:10.1067/S0016-5107(03)01962-X

48. Kommalapati A, Tella SH, Goyal G, Ma WW, Mahipal A. Contemporary management of localized resectable pancreatic cancer. Cancers (Basel). 2018;10(1). doi:10.3390/cancers10010024

49. Ducreux M, Cuhna AS, Caramella C, et al. Cancer of the pancreas: ESMO clinical practice guidelines for diagnosis, treatment and followup. Ann Oncol. 2015;26(suppl 5):v56-v68. doi:10.1093/annonc/ $\operatorname{mdv} 295$

50. Goetze TO. Gallbladder carcinoma: prognostic factors and therapeutic options. World J Gastroenterol. 2015;21(43):12211. doi:10.3748/wjg.v21.i43.12211

51. Malvezzi M, Bertuccio P, Levi F, La, Vecchia C, Negri E. European cancer mortality predictions for the year 2014. Ann Oncol. 2014;25 (8):1650-1656. doi:10.1093/annonc/mdu138

52. Polkowski M, Jenssen C, Kaye P, et al. Technical aspects of endoscopic ultrasound (EUS)-guided sampling in gastroenterology: European Society of Gastrointestinal Endoscopy (ESGE) Technical Guideline - march 2017. Endoscopy. 2017;49(10):9891006. doi:10.1055/s-0043-119219

53. Puli SR, Bechtold ML, Buxbaum JL, Eloubeidi MA. How good is endoscopic ultrasound-guided fine-needle aspiration in diagnosing the correct etiology for a solid pancreatic mass?: a meta-analysis and systematic review. Pancreas. 2013;42(1):20-26. doi:10.1097/ MPA.0b013e3182546e79 
54. Eloubeidi MA, Tamhane A, Varadarajulu S, Wilcox CM. Frequency of major complications after EUS-guided FNA of solid pancreatic masses: a prospective evaluation. Gastrointest Endosc. 2006;63(4):622-629.

55. Micames C, Jowell PS, White R, et al. Lower frequency of peritoneal carcinomatosis in patients with pancreatic cancer diagnosed by EUS-guided FNA vs. percutaneous FNA. Gastrointest Endosc. 2003;58(5):690-695.

56. Ikezawa $\mathrm{K}$, Uehara H, Sakai A, et al. Risk of peritoneal carcinomatosis by endoscopic ultrasound-guided fine needle aspiration for pancreatic cancer. $J$ Gastroenterol. 2013;48(8):966-972. doi:10.1007/s00535-012-0693-x

57. Wani S, Muthusamy VR, McGrath CM, et al. AGA white paper: optimizing endoscopic ultrasound-guided tissue acquisition and future directions. Clin Gastroenterol Hepatol. 2018;16(3):318327. doi:10.1016/j.cgh.2017.10.020

58. Navaneethan U, Njei B, Lourdusamy V, Konjeti R, Vargo JJ, Parsi MA. Comparative effectiveness of biliary brush cytology and intraductal biopsy for detection of malignant biliary strictures: a systematic review and meta-analysis. Gastrointest Endosc. 2015;81 (1):168-176.

59. Burnett AS, Calvert TJ, Chokshi RJ. Sensitivity of endoscopic retrograde cholangiopancreatography standard cytology: 10-y review of the literature. J Surg Res. 2013;184(1):304-311. doi:10.1016/j.jss.2013.06.028

60. Weilert F, Bhat YM, Binmoeller KF, et al. EUS-FNA is superior to ERCP-based tissue sampling in suspected malignant biliary obstruction: results of a prospective, single-blind, comparative study. Gastrointest Endosc. 2014;80(1):97-104. doi:10.1016/j.gie.2013.12.031

61. Mesrur Halefoglu A. Magnetic Resonance Cholangiopancreatography. Semin Roentgenol. 2008;43(4):282-289. doi:10.1053/j.ro.2008.06.004

62. Park M-S, Kim TK, Kim KW, et al. Differentiation of extrahepatic bile duct cholangiocarcinoma from benign stricture: findings at MRCP versus ERCP. Radiology. 2004;233(1):234-240. doi:10.1148/radiol.2331031446

63. Rösch T, Meining A, Frühmorgen S, et al. A prospective comparison of the diagnostic accuracy of ERCP, MRCP, CT, and EUS in biliary strictures. Gastrointest Endosc. 2002;55(7):870-876. doi:10.1067/mge.2002.124206

64. de Bellis M, Sherman S, Fogel EL, et al. Tissue sampling at ERCP in suspected malignant biliary strictures (Part 1). Gastrointest Endosc. 2002;56(4):a128132. doi:10.1016/S0016-5107(02)70123-5

65. de Bellis M, Sherman S, Fogel EL, et al. Tissue sampling at ERCP in suspected malignant biliary strictures (Part 2). Gastrointest Endosc. 2002;56(5):a129219. doi:10.1016/S0016-5107(02)70123-5

66. Baron TH, Harewood GC, Rumalla A, et al. A prospective comparison of digital image analysis and routine cytology for the identification of malignancy in biliary tract strictures. Clin Gastroenterol Hepatol. 2004;2(3):214-219. doi:10.1016/S1542-3565(04)00006-0

67. Kipp BR, Stadheim LM, Halling SA, et al. A comparison of routine cytology and fluorescence in situ hybridization for the detection of malignant bile duct strictures. Am J Gastroenterol. 2004;99 (9):1675-1681. doi:10.1111/j.1572-0241.2004.30281.x

68. Ponchon T, Gagnon P, Berger F, et al. Value of endobiliary brush cytology and biopsies for the diagnosis of malignant bile duct stenosis: results of a prospective study. Gastrointest Endosc. 1995;42(6):565-572. doi:10.1016/S0016-5107(95)70012-9

69. Tummala P, Munigala S, Eloubeidi MA, Agarwal B. Patients with obstructive jaundice and biliary stricture \pm mass lesion on imaging: prevalence of malignancy and potential role of EUS-FNA. J Clin Gastroenterol. 2013;47(6):532-537. doi:10.1097/MCG.0b013e3182 $745 \mathrm{~d} 9 \mathrm{f}$

70. Mohamadnejad M, DeWitt JM, Sherman S, et al. Role of EUS for preoperative evaluation of cholangiocarcinoma: a large single-center experience. Gastrointest Endosc. 2011;73(1):71-78. doi:10.1016/j. gie.2010.08.050
71. Hewitt MJ, MJW M, Possamai L, Dhar A, Vlavianos P, Monahan KJ. EUS-guided FNA for diagnosis of solid pancreatic neoplasms: a meta-analysis. Gastrointest Endosc. 2012;75(2):319-331. doi:10.1016/j.gie.2011.08.049

72. Ma MX, Jayasekeran V, Chong AK. Benign biliary strictures: prevalence, impact, and management strategies. Clin Exp Gastroenterol. 2019;12:83-92. doi:10.2147/CEG.S165016

73. Chang M-C, Liang P-C, Jan S, et al. Increase diagnostic accuracy in differentiating focal type autoimmune pancreatitis from pancreatic cancer with combined serum IgG4 and CA19-9 levels. Pancreatology. 2014;14(5):366-372. doi:10.1016/j.pan.2014.07.010

74. Chari ST, Takahashi N, Levy MJ, et al. A diagnostic strategy to distinguish autoimmune pancreatitis from pancreatic cancer. Clin Gastroenterol Hepatol. 2009;7(10):1097-1103. doi:10.1016/j. cgh.2009.04.020

75. Parsa N, Khashab MA. The role of peroral cholangioscopy in evaluating indeterminate biliary strictures. Clin Endosc. 2019. doi:10.5946/ce.2019.011

76. Robles-Medranda C, Valero M, Soria-Alcivar M, et al. Reliability and accuracy of a novel classification system using peroral cholangioscopy for the diagnosis of bile duct lesions. Endoscopy. 2018;50:1059-1070.

77. Kim HJ, Kim MH, Lee SK, Yoo KS, Seo DW, Min YI. Tumor vessel: a valuable cholangioscopic clue of malignant biliary stricture. Gastrointest Endosc. 2000;52(5):635-638. doi:10.1067/ mge.2000.108969

78. Itoi T, Osanai M, Igarashi $\mathrm{Y}$, et al. Diagnostic peroral video cholangioscopy is an accurate diagnostic tool for patients with bile duct lesions. Clin Gastroenterol Hepatol. 2010;8(11):934-938. doi:10.1016/j. cgh.2010.06.029

79. Mizrahi M, Khoury T, Wang Y, et al. "Apple Far from the Tree": comparative effectiveness of fiberoptic single-operator cholangiopancreatoscopy (FSOCP) and digital SOCP (DSOCP). HPB (Oxford). 2018;20(3):285-288. doi:10.1016/j.hpb.2017.09.002

80. Krishna NB, Saripalli S, Safdar R, Agarwal B. Intraductal US in evaluation of biliary strictures without a mass lesion on CT scan or magnetic resonance imaging: significance of focal wall thickening and extrinsic compression at the stricture site. Gastrointest Endosc. 2007;66(1):90-96. doi:10.1016/j.gie.2006.10.020

81. Turowski F, Hügle U, Dormann A, et al. Diagnostic and therapeutic single-operator cholangiopancreatoscopy with SpyGlassDS $^{\mathrm{TM}}$ : results of a multicenter retrospective cohort study. Surg Endosc. 2018;32(9):3981-3988. doi:10.1007/s00464-018-6141-0

82. Tamada K, Ueno N, Tomiyama T, et al. Characterization of biliary strictures using intraductal ultrasonography: comparison with percutaneous cholangioscopic biopsy. Gastrointest Endosc. 1998;47 (5):341-349. doi:10.1016/S0016-5107(98)70216-0

83. Tabibian JH, Visrodia KH, Levy MJ, Gostout CJ. Advanced endoscopic imaging of indeterminate biliary strictures. World $J$ Gastrointest Endosc. 2015;7(18):1268. doi:10.4253/wjge.v7. i18.1268

84. Meister T, Heinzow HS, Woestmeyer C, et al. Intraductal ultrasound substantiates diagnostics of bile duct strictures of uncertain etiology. World J Gastroenterol. 2013;19(6):874-881. doi:10.3748/ wjg.v19.i6.874

85. Baron TH, Mallery JS, Hirota WK, et al. The role of endoscopy in the evaluation and treatment of patients with pancreaticobiliary malignancy. Gastrointest Endosc. 2003;58(5):643-649. doi:10.1016/S0016-5107 (03)01994-1

86. Sewnath ME, Karsten TM, Prins MH, Rauws EJA, Obertop H, Gouma DJ. A meta-analysis on the efficacy of preoperative biliary drainage for tumors causing obstructive jaundice. Ann Surg. 2002;236(1):17-27. doi:10.1097/00000658-200207000-00005

87. van der Gaag NA, Rauws EAJ, CHJ VE, et al. Preoperative biliary drainage for cancer of the head of the pancreas. $N$ Engl $J$ Med. 2010;362(2):129-137. doi:10.1056/NEJMoa0903230 
88. Lee PJ, Podugu A, Wu D, Lee AC, Stevens T, Windsor JA. Preoperative biliary drainage in resectable pancreatic cancer: a systematic review and network meta-analysis. HPB. 2018;20 (6):477-486. doi:10.1016/j.hpb.2017.12.007

89. Dumonceau J-M, Tringali A, Papanikolaou I, et al. Endoscopic biliary stenting: indications, choice of stents, and results: European Society of Gastrointestinal Endoscopy (ESGE) Clinical Guideline - updated October 2017. Endoscopy. 2018;50(09):910930. doi:10.1055/a-0659-9864

90. Sauvanet A, Boher J-M, Paye F, et al. Severe jaundice increases early severe morbidity and decreases long-term survival after pancreaticoduodenectomy for pancreatic adenocarcinoma. $J$ Am Coll Surg. 2015;221(2):380-389. doi:10.1016/j.jamcollsurg.2015.03.058

91. Arkadopoulos N, Kyriazi MA, Papanikolaou IS, et al. Preoperative biliary drainage of severely jaundiced patients increases morbidity of pancreaticoduodenectomy: results of a case-control study. World J Surg. 2014;38(11):2967-2972. doi:10.1007/s00268-014-2669-x

92. Takahashi $Y$, Nagino $M$, Nishio H, Ebata T, Igami T, Nimura $Y$. Percutaneous transhepatic biliary drainage catheter tract recurrence in cholangiocarcinoma. $B r \quad J$ Surg. 2010;97(12):1860-1866. doi:10.1002/bjs.v97:12

93. Miura F, Sano K, Wada K, et al. Prognostic impact of type of preoperative biliary drainage in patients with distal cholangiocarcinoma. Am J Surg. 2017;214(2):256-261. doi:10.1016/j.amjsurg.2017.01.010

94. Strom TJ, Klapman JB, Springett GM, et al. Comparative longterm outcomes of upfront resected pancreatic cancer after preoperative biliary drainage. Surg Endosc. 2015;29(11):3273-3281. doi:10.1007/s00464-015-4075-3

95. Uemura K, Murakami Y, Satoi S, et al. Impact of preoperative biliary drainage on long-term survival in resected pancreatic ductal adenocarcinoma: a multicenter observational study. Ann Surg Oncol. 2015;22(Suppl 3(S3)):S1238-S1246. doi:10.1245/s10434015-4618-9

96. Crippa S, Cirocchi R, Partelli S, et al. Systematic review and metaanalysis of metal versus plastic stents for preoperative biliary drainage in resectable periampullary or pancreatic head tumors. Eur J Surg Oncol. 2016;42(9):1278-1285. doi:10.1016/j.ejso.2016.05.001

97. Song TJ, Lee JH, Lee SS, et al. Metal versus plastic stents for drainage of malignant biliary obstruction before primary surgical resection. Gastrointest Endosc. 2016;84(5):814-821. doi:10.1016/j. gie.2016.04.018

98. Tol JAMG, van Hooft JE, Timmer R, et al. Metal or plastic stents for preoperative biliary drainage in resectable pancreatic cancer. Gut. 2016;65(12):1981-1987. doi:10.1136/gutjnl-2014-308762

99. Gardner TB, Spangler CC, Byanova KL, et al. Cost-effectiveness and clinical efficacy of biliary stents in patients undergoing neoadjuvant therapy for pancreatic adenocarcinoma in a randomized controlled trial. Gastrointest Endosc. 2016;84(3):460-466. doi:10.1016/j.gie.2016.02.047

100. Adams MA, Anderson MA, Myles JD, Khalatbari S, Scheiman JM. Self-expanding metal stents (SEMS) provide superior outcomes compared to plastic stents for pancreatic cancer patients undergoing neoadjuvant therapy. J Gastrointest Oncol. 2012;3(4):309-313. doi:10.3978/j.issn.2078-6891.2011.050

101. Tsuboi T, Sasaki T, Serikawa M, et al. Preoperative biliary drainage in cases of borderline resectable pancreatic cancer treated with neoadjuvant chemotherapy and Surgery. Gastroenterol Res Pract. 2016;2016:7968201. doi:10.1155/2016/7968201

102. Seo DW, Sherman S, Dua KS, et al. Covered and uncovered biliary metal stents provide similar relief of biliary obstruction during neoadjuvant therapy in pancreatic cancer: a randomized trial. Gastrointest Endosc. 2019. (Epub ahead of print). doi:10.1016/j. gie.2019.06.032

103. Cavell LK, Allen PJ, Vinoya C, et al. Biliary self-expandable metal stents do not adversely affect pancreaticoduodenectomy. Am J Gastroenterol. 2013;108(7):1168-1173. doi:10.1038/ajg.2013.93
104. Abraham NS, Barkun JS, Barkun AN. Palliation of malignant biliary obstruction: a prospective trial examining impact on quality of life. Gastrointest Endosc. 2002;56(6):a129868. doi:10.1016/ S0016-5107(02)70356-8

105. Distler M, Kersting S, Rückert F, et al. Palliative treatment of obstructive jaundice in patients with carcinoma of the pancreatic head or distal biliary tree. Endoscopic stent placement vs. hepaticojejunostomy. JOP. 2010;11(6):568-574.

106. Ho CS, Warkentin AE. Evidence-based decompression in malignant biliary obstruction. Korean J Radiol. 2012;13(Suppl 1):S56S61. doi:10.3348/kjr.2012.13.S1.S56

107. Taylor MC, McLeod RS, Langer B. Biliary stenting versus bypass surgery for the palliation of malignant distal bile duct obstruction: a meta-analysis. Liver Transpl. 2000;6(3):302-308. doi:10.1053/ lv. 2000.5196

108. Lucia Alves de Lima S, Alberto Castillo Bustamante F, Guimarães Hourneaux de Moura E, et al. Endoscopic palliative treatment versus surgical bypass in malignant low bile duct obstruction: a systematic review and meta-analysis. Int $J$ Hepatobiliary Pancreat Dis. 2015;5:35-46.

109. Glazer ES, Hornbrook MC, Krouse RS. A meta-analysis of randomized trials: immediate stent placement vs. surgical bypass in the palliative management of malignant biliary obstruction. $J$ Pain Symptom Manage. 2014;47(2):307-314. doi:10.1016/j. jpainsymman.2013.03.013

110. Inamdar S, Slattery E, Bhalla R, Sejpal DV, Trindade AJ. Comparison of adverse events for endoscopic vs percutaneous biliary drainage in the treatment of malignant biliary tract obstruction in an inpatient national cohort. JAMA Oncol. 2016;2(1):112. doi:10.1001/jamaoncol.2015.3670

111. Moole H, Jaeger A, Cashman M, et al. Are self-expandable metal stents superior to plastic stents in palliating malignant distal biliary strictures? A meta-analysis and systematic review. Med J Armed Forces India. 2017;73(1):42-48. doi:10.1016/j. mjafi.2016.08.014

112. Pu L Z, EGH DM, Bernardo WM, et al. Endoscopic stenting for inoperable malignant biliary obstruction: A systematic review and meta-analysis. World J Gastroenterol. 2015;21(47):13374-13385. doi:10.3748/wjg.v21.i47.13374

113. Hong W, Chen X, Wu W-Z, Zhu Q, Chen X. Metal versus plastic stents for malignant biliary obstruction: an update meta-analysis. Clin Res Hepatol Gastroenterol. 2013;37(5):496-500. doi:10.1016/ j.clinre.2012.12.002

114. Almadi MA, Barkun A, Martel M. Plastic vs. self-expandable metal stents for palliation in malignant biliary obstruction: a series of metaanalyses. Am J Gastroenterol. 2017;112(2):260-273. doi:10.1038/ ajg. 2016.512

115. Sawas T, Al Halabi S, Parsi MA, Vargo JJ. Self-expandable metal stents versus plastic stents for malignant biliary obstruction: a meta-analysis. Gastrointest Endosc. 2015;82(2):256-267.e7. doi:10.1016/j.gie.2015.03.1980

116. Walter D, PGA VB, Groenen MJM, et al. Higher quality of life after metal stent placement compared with plastic stent placement for malignant extrahepatic bile duct obstruction. Eur J Gastroenterol Hepatol. 2017;29(2):231-237. doi:10.1016/S0016-5107(03)02009-1

117. Walter D, PGA VB, Groenen MJ, et al. Cost efficacy of metal stents for palliation of extrahepatic bile duct obstruction in a randomized controlled trial. Gastroenterology. 2015;149(1):130-138. doi:10.1053/j. gastro.2015.03.012

118. Chen M-Y, Lin J-W, Zhu H-P, et al. Covered stents versus uncovered stents for unresectable malignant biliary strictures: a metaanalysis. Biomed Res Int. 2016;2016:6408067.

119. Moole H, Bechtold ML, Cashman M, et al. Covered versus uncovered self-expandable metal stents for malignant biliary strictures: A meta-analysis and systematic review. Indian $J$ Gastroenterol. 2016;35(5):323-330. doi:10.1007/s12664-016-0682-8 
120. Li J, Li T, Sun P, et al. Covered versus uncovered self-expandable metal stents for managing malignant distal biliary obstruction: a meta-analysis. Green J, ed. PLoS One. 2016;11(2):e0149066. doi:10.1371/journal.pone.0149066

121. Alastal Y, Hammad TA, Khan MA, et al. Risk of post-ERCP pancreatitis after placement of covered versus uncovered selfexpandable biliary metal stents: a systematic review and metaanalysis. JOP. 2015;16:452-458.

122. Saleem A, Leggett CL, Murad MH, Baron TH. Meta-analysis of randomized trials comparing the patency of covered and uncovered self-expandable metal stents for palliation of distal malignant bile duct obstruction. Gastrointest Endosc. 2011;74(2):321-327.e1-3. doi:10.1016/j.gie.2011.03.1249

123. Almadi MA, Barkun AN, Martel M. No benefit of covered vs uncovered self-expandable metal stents in patients with malignant distal biliary obstruction: a meta-analysis. Clin Gastroenterol Hepatol. 2013;11(1):27-37.e1. doi:10.1016/j.cgh.2012.10.019

124. Yang Z, Wu Q, Wang F, Ye X, Qi X, Fan D. A systematic review and meta-analysis of randomized trials and prospective studies comparing covered and bare self-expandable metal stents for the treatment of malignant obstruction in the digestive tract. Int $\mathrm{J}$ Med Sci. 2013;10(7):825-835. doi:10.7150/ijms.5969

125. Tringali A, Hassan C, Rota M, Rossi M, Mutignani M, Aabakken L. Covered vs. uncovered self-expandable metal stents for malignant distal biliary strictures: a systematic review and meta-analysis. Endoscopy. 2018;50(06):631-641. doi:10.1055/s-0043-125062

126. Conio M, Mangiavillano B, Caruso A, et al. Covered versus uncovered self-expandable metal stent for palliation of primary malignant extrahepatic biliary strictures: a randomized multicenter study. Gastrointest Endosc. 2018;88(2):283-291.e3. doi:10.1016/j. gie.2018.03.029

127. Jang SI, Lee SJ, Jeong S, et al. Efficacy of a multiplex paclitaxel emission stent using a pluronic ${ }^{\circledR}$ mixture membrane versus a covered metal stent in malignant biliary obstruction: a prospective randomized comparative study. Gut Liver. 2017;11(4):567-573. doi: $10.5009 /$ gnl16428

128. Lee YN, Moon JH, Choi HJ, et al. Effectiveness of a newly designed antireflux valve metal stent to reduce duodenobiliary reflux in patients with unresectable distal malignant biliary obstruction: a randomized, controlled pilot study (with videos). Gastrointest Endosc. 2016;83 (2):404 412. doi:10.1016/j.gie.2015.08.084

129. Park DH, Lee SS, Lee TH, et al. Anchoring flap versus flared end, fully covered self-expandable metal stents to prevent migration in patients with benign biliary strictures: a multicenter, prospective, comparative pilot study (with videos). Gastrointest Endosc. 2011;73(1):64-70. doi:10.1016/j.gie.2010.09.039

130. Minaga K, Kitano M, Imai $\mathrm{H}$, et al. Evaluation of anti-migration properties of biliary covered self-expandable metal stents. World $J$ Gastroenterol. 2016;22(30):6917-6924. doi:10.3748/wjg.v22.i30.6917

131. Sharaiha RZ, Khan MA, Kamal F, et al. Efficacy and safety of EUS-guided biliary drainage in comparison with percutaneous biliary drainage when ERCP fails: a systematic review and metaanalysis. Gastrointest Endosc. 2017;85(5):904-914. doi:10.1016/j. gie.2016.12.023

132. Hindryckx P, Degroote H, Tate DJ, Deprez PH. Endoscopic ultrasound-guided drainage of the biliary system: techniques, indications and future perspectives. World J Gastrointest Endosc. 2019;11 (2):103-114. doi:10.4253/wjge.v11.i2.103
133. Khan MA, Akbar A, Baron TH, et al. Endoscopic ultrasoundguided biliary drainage: a systematic review and meta-analysis. Dig Dis Sci. 2016;61(3):684-703. doi:10.1007/s10620-015-3933-0

134. Fabbri C, Luigiano C, Lisotti A, et al. Endoscopic ultrasoundguided treatments: are we getting evidence based-a systematic review. World J Gastroenterol. 2014;20(26):8424-8448. doi:10.3748/wjg.v20.i26.8424

135. Paik WH, Lee TH, Park DH, et al. EUS-guided biliary drainage versus ERCP for the primary palliation of malignant biliary obstruction: a multicenter randomized clinical trial. $A m J$ Gastroenterol. 2018;113(7):987-997. doi:10.1038/s41395-0180122-8

136. Bang JY, Navaneethan U, Hasan M, Hawes R, Varadarajulu S. Stent placement by EUS or ERCP for primary biliary decompression in pancreatic cancer: a randomized trial (with videos). Gastrointest Endosc. 2018;88(1):9-17. doi:10.1016/j.gie.2018.03.012

137. Park JK, Woo YS, Noh DH, et al. Efficacy of EUS-guided and ERCP-guided biliary drainage for malignant biliary obstruction: prospective randomized controlled study. Gastrointest Endosc. 2018;88(2):277-282. doi:10.1016/j.gie.2018.03.015

138. Nabi Z, Reddy DN. Endoscopic palliation for biliary and pancreatic malignancies: recent advances. Clin Endosc. 2019;52(3):226-234. doi:10.5946/ce.2019.003

139. Dolak W, Schreiber F, Schwaighofer H, et al. Endoscopic radiofrequency ablation for malignant biliary obstruction: a nationwide retrospective study of 84 consecutive applications. Surg Endosc. 2014;28(3):854-860. doi:10.1007/s00464-013-3232-9

140. Yang J, Wang J, Zhou H, et al. Efficacy and safety of endoscopic radiofrequency ablation for unresectable extrahepatic cholangiocarcinoma: a randomized trial. Endoscopy. 2018;50(8):751-760. doi: $10.1055 / \mathrm{s}-0043-124870$

141. Sofi AA, Khan MA, Das A, et al. Radiofrequency ablation combined with biliary stent placement versus stent placement alone for malignant biliary strictures: a systematic review and meta-analysis. Gastrointest Endosc. 2018;87(4):944-951.e1. doi:10.1016/j. gie.2017.10.029

142. Ortner MEJ, Caca K, Berr F, et al. Successful photodynamic therapy for nonresectable cholangiocarcinoma: a randomized prospective study. Gastroenterology. 2003;125(5):1355-1363. doi:10.1016/j.gastro.2003.07.015

143. Kiesslich T, Wolkersdörfer G, Neureiter D, Salmhofer H, Berr F. Photodynamic therapy for non-resectable perihilar cholangiocarcinoma. Photochem Photobiol Sci. 2009;8(1):23-30. doi:10.1039/ B813183J

144. Kahaleh M, Mishra R, Shami VM, et al. Unresectable cholangiocarcinoma: comparison of survival in biliary stenting alone versus stenting with photodynamic therapy. Clin Gastroenterol Hepatol. 2008;6(3):290-297. doi:10.1016/j.cgh.2007.12.004

145. Cui P-J, Yao J, Zhao Y-J, Han H-Z YJ. Biliary stenting with or without sphincterotomy for malignant biliary obstruction: A metaanalysis. World J Gastroenterol. 2014;20(38):14033. doi:10.3748/ wjg.v20.i38.14033

146. Sofi AA, Nawras A, Alaradi OH, Alastal Y, Khan MA, Lee WM. Does endoscopic sphincterotomy reduce the risk of post-endoscopic retrograde cholangiopancreatography pancreatitis after biliary stenting? A systematic review and meta-analysis. Dig Endosc. 2016;28(4):394-404. doi:10.1111/den.12584 


\section{Publish your work in this journal}

Clinical and Experimental Gastroenterology is an international, peerreviewed, open access, online journal publishing original research, reports, editorials, reviews and commentaries on all aspects of gastroenterology in the clinic and laboratory. This journal is indexed

The manuscript management system is completely online and includes a very quick and fair peer-review system, which is all easy to use. Visit http://www.dovepress.com/testimonials.php to on American Chemical Society's Chemical Abstracts Service (CAS). read real quotes from published authors.

Submit your manuscript here: https://www.dovepress.com/clinical-and-experimental-gastroenterology-journal 